\title{
GAIFEROS DE MORMALTÁN Y EL DUQUE GUILLERMO X DE AQUITANIA: ENTRE JOFRE DE MONMOUTH Y MANUEL MURGUÍA
}

\author{
José MARÍA ANGUITA JAÉN \\ Universidad de Santiago de Compostela \\ ORCID iD: http://orcid.org/0000-0002-8391-3483
}

\begin{abstract}
Copyright: (C) 2021 CSIC. La edición electrónica de esta revista se distribuye bajo los términos de una licencia de uso y distribución Creative Commons Reconocimiento 4.0 Internacional (CC BY 4.0).

Cómo citar/Citation: José María ANGUITA JAÉN, “Gaiferos de Mormaltán y el duque Guillermo X de Aquitania: entre Jofre de Monmouth y Manuel Murguía”, Cuadernos de Estudios Gallegos, 68, núm. 134 (2021), págs. 91-123, https://doi.org/10.3989/ceg.2021.134.03
\end{abstract}




\title{
GAIFEROS DE MORMALTÁN Y EL DUQUE GUILLERMO X DE AQUITANIA: ENTRE JOFRE DE MONMOUTH Y MANUEL MURGUÍA
}

\begin{abstract}
RESUMEN
Desde su hallazgo por Manuel Murguía, el Don Gaiferos de Mormaltán es la pieza más popular del repertorio romancístico gallego, a pesar de que los especialistas en literatura de tradición oral lo hayan señalado como producto no genuino. En este trabajo se mostrará que, a pesar de que este juicio pueda estar bien fundamentado, es muy probable que un suceso como la peregrinación y muerte de Guillermo X de Aquitania en Compostela el año 1137 diera lugar a un material literario emparentado con el que da cuerpo al Don Gaiferos. Se pondrá además en relación al Gaiferos gallego con el Gaiferos de los romances viejos castellanos, de peripecia aparentemente tan disímil, a partir de la constatación de que ambos incorporan rasgos biográficos de los históricos duques de Aquitania de los siglos XI y XII. Se mostrará, finalmente, cómo el último duque aquitano, Guillermo X, pudo ser efectivamente conocido por el sobrenombre de Gaiferos, a partir de la alusión malévola que Jofre de Monmouth hace de él bajo la figura de Goffarius Pictus (Historia regum Britanniae 1, 18-20). Se concluye que a Murguía llegó, no sabemos por qué medios ni en qué estado, un material literario antiguo a partir del cual compuso su Gaiferos de Mormaltán. Este sería, por tanto, una versión facticia compuesta a partir de elementos tradicionales, y no una simple falsificación.

Palabras Clave: Romance de Don Gaiferos, Jofre de Monmouth, Guillermo X de Aquitania, literatura tradicional, Manuel Murguía.
\end{abstract}

\section{GAIFEROS DE MORMALTÁN E O DUQUE GUILLERME X DE AQUITANIA: ENTRE XOFRE DE MONMOUTH E MANUEL MURGUÍA}

\section{RESUMO}

Dende o seu descubrimento por Manuel Murguía, o Don Gaiferos de Mormaltán é a peza máis popular do repertorio romancístico galego, a pesar de que os especialistas en literatura de tradición oral sinalárono como produto non xenuíno. Neste traballo mostrarase que, a pesar de que este xuízo poida estar ben fundamentado, é moi probable que un suceso como a peregrinación e morte de Guillerme X de Aquitania en Compostela o ano 1137 dese lugar a un material literario emparentado co que dá corpo ao Don Gaiferos. Poñerase ademais en relación o Gaiferos galego co Gaiferos dos romances vellos casteláns, de peripecia aparentemente tan disímil, a partir da constatación de que ambos incorporan trazos biográficos dos históricos duques de Aquitania dos séculos XI y XII. Mostrarase, finalmente, como o último duque aquitano, Guillerme X, puido ser efectivamente coñecido polo sobrenome de Gaiferos, a partir da alusión malévola que Xofre de Monmouth fai del baixo a figura de Goffarius Pictus (Historia regum Britanniae 1, 18-20). Conclúese que a Murguía chegou, non sabemos por que medios nin en que estado, un material literario antigo a partir do cal compuxo o seu Gaiferos de Mormaltán. Este sería, por tanto, unha versión facticia composta a partir de elementos tradicionais, e non unha simple falsificación.

Palabras clave: Romance de Don Gaiferos, Xofre de Monmouth, Guillerme X de Aquitania, literatura tradicional, Manuel Murguía.

\section{GAIFEROS DE MORMALTÁN AND WILLIAM X OF AQUITAINE: BETWEEN GEOFFREY OF MONMOUTH AND MANUEL MURGUÍA}

ABSTRACT

Don Gaiferos de Mormaltán has been the most popular piece in the Galician ballad repertoire since its discovery by Manuel Murguía, despite having been dismissed as a spurious artefact by specialists in literature of oral tradition. Although this dismissal may be well founded, this essay will show that the pilgrimage and death of William X of Aquitaine in Compostela in 1137 are likely to have inspired a body of literary material related to Don Gaiferos. Moreover, this article will link the Galician Gaiferos with the Gaiferos of the old Castilian ballads, who appears to be so different, based on the proven fact that both include biographical features of the historical dukes of Aquitaine in the $11^{\text {th }}$ and $12^{\text {th }}$ centuries. Finally, the paper will show how William X, the last duke of Aquitaine, might have been known by the nickname Gaiferos, stemming from the malicious reference that Geoffrey of Monmouth makes of him through the figure of Goffarius Pictus (Historia regum Britanniae 1, 18-20). The essay will conclude that a body of ancient literary material reached Murguía, we do not know how or in what condition, and served as a basis for his Don Gaiferos de Mormaltán. Therefore, this would be a factitious version made up of traditional elements, and not a simple forgery. KEY WORDS: Ballad of Don Gaiferos, Geoffrey of Monmouth, William X of Aquitaine, oral literature, Manuel Murguía. 
Recibido/Received: 30/06/2020

Aceptado/Accepted: 25/10/2020

\section{El Romance de Don Gaiferos de Manuel Murguía y la CRítica}

En 1888, Manuel Murguía daba a la imprenta el Romance de Don Gaiferos, pieza de carácter excepcional por dos motivos: en su momento, por constituirse en una de las primeras muestras gallegas del género; desde siempre, por ser la única de temática jacobea. Llama la atención cómo el escritor lo dio a la publicidad de forma casi subrepticia en su monumental Galicia, un asunto más entre mil dentro de un prolijo y abigarrado capítulo dedicado a las peregrinaciones a Santiago, en medio de una colorida escena costumbrista a las puertas de la catedral, donde ciegos y juglares entonan para los peregrinos cantinelas noticiosas de acontecimientos relacionados con el sepulcro del Apóstol. Es ahí donde, tras unas exclamaciones que ponderan el valor de ese repertorio perdido, Murguía da la gran noticia:

Uno se conserva, que ha llegado hasta nosotros: lo damos como prueba de la importancia que debieron tener, lo damos también como muestra de la poesía tradicional y del pueblol.

Sin embargo, una vez transcrito y mínimamente glosado el poema, este queda inmediatamente olvidado, sepultado bajo otra acumulación de espectáculos y representaciones populares en torno a la iglesia, farsas y autos sacramentales, danzas y procesiones. La frustrante impresión que queda en el lector ávido de noticias sobre la procedencia y las circunstancias del sensacional descubrimiento es la de que Murguía, su autor y único testigo, le ha hurtado una información fundamental.

Esta es, quizá, la razón principal de que los especialistas en literatura tradicional hayan rechazado la autenticidad del Don Gaiferos², pero no la única. Análisis

\footnotetext{
${ }^{1}$ Manuel Murguía, Galicia, Barcelona, Establecimiento tipográfico-editorial de Daniel Cortezo y C. , 1888 (España. Sus monumentos y artes, su naturaleza é historia), págs. 423-424.

2 Diego Catalán, et al., Catálogo General del Romancero. Vol. 1: Teoría general y metodología del Romancero Pan-hispánico: catálogo general descriptivo, Madrid, Seminario Menéndez-Pidal, 1983, pág. 30; Ana Valenciano, Romancero Xeral de Galicia. Os romances tradicionais de Galicia, Santiago
} 
de lengua y estilo han contribuido a apuntalar este juicio ${ }^{3}$, del mismo modo que también lo ha hecho la llamativa evolución (1856-1888) del pensamiento de Murguía en torno al género del romance, negando al principio su propia existencia en Galicia para, admitido esto último, terminar sosteniendo su peculiaridad celtogermánica frente al resto del romancero general hispánico ${ }^{4}$. Todo ello sumado ha llevado a la conclusión de que el Don Gaiferos no es una pieza tradicional, sino una falsificación elaborada por el propio Murguía o por alguien de su entorno.

Ante esto, lo normal hubiera sido que el Romance de Don Gaiferos hubiera sido retirado discretamente de la escena pública y dejado de promocionar e interpretar como lo que no es, es decir, como un producto tradicional genuino. Esto no solo no ha ocurrido, sino que, bien al contrario, puede decirse que, del catálogo de romances trabajosamente rescatados de la oralidad en ámbito gallego, el presunto falso de Murguía sigue siendo el más conocido y apreciado en todos los niveles, populares e intelectuales. Aunque es posible que semejante empeño tenga motivaciones ajenas al valor intrínseco del romance, sin embargo, ha de admitirse que la promoción y el cultivo del Don Gaiferos como muestra genuina del patrimonio literario gallego medieval no carece absolutamente de razones, aunque estas se basen principalmente en la belleza de un tema que, se non è vero è ben trovato ${ }^{5}$. Entre las últimas y mejores defensas de la autenticidad del Don Gaiferos y, por extensión, de la probidad filológica de Murguía, destaca el libro de Isidoro Millán González-Pardo, conde de Quirós, Don Gaiferos de Mormaltán. X Duque de Aquitania ${ }^{6}$. Este meritorio estudio, publicado de forma

de Compostela; Madrid, Centro de Investigaciones Ramón Piñeiro; Fundación Ramón Menéndez Pidal, 1998, págs. 68-69; José Luis ForNEIRo, El Romancero tradicional de Galicia, una poesía entre dos lenguas, Oiartzun, Sendoa, 2000, págs. 35-45.

3 José Luis Forneiro, "Mais textos para a produçâo de Murguía em lingua galega", en Congreso sobre Manuel Murguía, Santiago de Compostela, Consellería de Cultura, Comunicación social e Turismo, 2001, págs. 169-188; José Luis ForneIRo, “Gaiferos de Mormaltán: Cantiga medieval? Romance tradicional?" Vieiros [en línea] (06/05/2010), disponible en <http://www.vieiros.com/columnas/opinion/1198/ gaiferos-de-mormaltan-cantiga-medieval-romance-tradicional> [Consulta: 11/03/2020].

4 José Luis Forneiro, "El Romancero tradicional de Galicia. Estado de la cuestión”, Boletín de Literatura Oral, 1 (2017), págs. 105-130.

5 Esta postura queda irónicamente reflejada en este diálogo teatral del poeta Claudio Rodríguez Fer:

"A: ¿Cómo sería o Antigo Reino de Galicia?

P: Como o das Mil e Unha Noites.

A: Non, como o do Romance de don Gaiferos de Mormaltán, a máxima expresión popular da poesia en Galícia.

P: Por algo o inventou Murguía.

A: ¿Qué dis? ¿Acaso cres que non é popular?

P: Claro que non é popular, aínda que debera."

Claudio Rodríguez Fer, "O pornógrafo", Primeiras xornadas de Teatro na Radio. 17 a 19 de maio de 1989, Lugo, Radio 5; Caixa Galicia, 1989, [s. p.].

${ }^{6}$ Isidoro Millán GonzÁlez-Pardo, Don Gaiferos de Mormaltán, X Duque de Aquitania, Santiago de Compostela, Follas Novas, 2009. 
póstuma a partir de una copia "precisada aún de acabamiento y revisión cuidadosa de todas sus páginas" pretensión de mostrar que una cosa es el argumento del Don Gaiferos, que no solo es bello sino que también puede ser perfectamente auténtico, y otra es el tratamiento del mismo por Murguía, que dio como resultado el romance puesto en solfa por la crítica.

El objetivo del conde de Quirós de probar la autenticidad del Don Gaiferos a partir de argumentos literarios se queda en mero voluntarismo, en buena medida por ignorar el análisis filológico que ha diseccionado el poema y puesto en evidencia sus rasgos no tradicionales. Por la parte contraria, su trabajo aporta una interesante línea de estudio sobre las fuentes historiográficas que sirvieron a Murguía para identificar a Gaiferos con Guillermo X, a partir de la concordancia argumental del romance - un noble peregrino francés llega extenuado a Santiago y muere ante el altar del Apóstol-, con la historia real del duque aquitano. Mediante ese estudio Millán González-Pardo reveló la pobreza del bagaje erudito de Murguía en este punto, deduciendo de ahí que alguien que desconocía absolutamente las fuentes en torno a la peregrinación y muerte de Guillermo X, no había podido crear de la nada una pieza cuyo argumento se basa precisamente en esos hechos. La deducción es correcta, pero solo en parte, por no pararse a distinguir la antigüedad del material literario que da cuerpo a la pieza con la propia pieza en sí. Sobre la antigüedad de esos materiales literarios basados en acontecimientos históricos se trata a continuación.

\section{LA PEREGRINACIÓN Y MUERTE DE GUILlERMO X DE AQUiTANiA. DESDE SUS CONTEMPORÁNEOS AL TIEMPO DE MURGUÍA}

La muerte del duque Guillermo X de Aquitania, uno de los magnates más poderosos de su tiempo, tuvo consecuencias políticas de enorme relevancia: poco después de fallecer, su hija Leonor se casaba en Burdeos, el 25 de julio de 1137, con el heredero de la corona de Francia, el futuro Luis VII. Con esta unión dinástica, los extensísimos feudos heredados por Leonor pasaban a formar parte del Reino de Francia, tal como refleja en su Crónica de la abadía de Vézélay un paisano del duque fallecido, Hugo Pictavino. En el parágrafo de esta obra dedicado a Luis VII no se hace, sin embargo, alusión alguna a su muerte y sus circunstancias:

Viene después el rey Luis [VII], cuyo padre Luis [VI] engrandeció su reino por todas sus fronteras al darle en matrimonio a la hija

\footnotetext{
${ }^{7}$ Millán, Don Gaiferos..., pág. 10.
} 
del duque de Aquitania y conde de Poitiers, por la cual adquirió toda Aquitania, Gascuña, el País Vasco Francés y Navarra hasta los Montes Pirineos y la Cruz de Carlomagno ${ }^{8}$.

En cualquier caso, la muerte del dueño de más de la mitad del territorio galo es un acontecimiento que no podía dejar de ser consignado por los cronistas de la época. El abad Sugero de Saint-Denis, consejero y cronista de Luis VI, fue de los primeros en conocer de forma oficial la noticia, trasladada al rey por una embajada de nobles aquitanos. Gracias a su relato prácticamente contemporáneo de los hechos, sabemos que la muerte de Guillermo se produjo en circunstancias excepcionales, en el curso de una peregrinación a Santiago:

Habiendo llegado [el rey Luis VI] al castillo de Béthisy, le siguieron a toda prisa los legados de Guillermo, duque de Aquitania, con la noticia de que el duque había salido en peregrinación a Santiago y había muerto en el camino, pero que antes de emprender la ruta, y después en el propio camino, cuando ya estaba en trance de morir, había considerado y dispuesto que su nobilísima hija, de nombre Leonor, tendría que casarse, pues ella iba a ser la heredera de todos sus dominios. [Luis VI], tras deliberar con sus allegados y aceptar el ofrecimiento con alegría y su habitual altura de miras, prometió que la casaría con su querido hijo Luis ${ }^{9}$.

Sugero no se detiene en la inusual muerte del duque peregrino, pues esta no interesa a su relato más que por sus repercusiones en el Reino de Francia, aparte de que el suceso viene consignado entre otros acontecimientos de gran relevancia, como la propia muerte del viejo rey Luis VI poco después de su entrevista con los embajadores aquitanos, o el casamiento en Burdeos de Luis VII y Leonor, al que Sugero asistió como parte del séquito del príncipe. La Crónica

\footnotetext{
${ }^{8}$ Hvgo Pictavinvs, Chronicon abbatiae Vizeliacensis, ed. Robert B.C. Huygens, Monumenta Veziliacensia: textes relatifs a l'histoire de l'abbaye de Vézelay, Turnhout, Brepols, 1976 (Corpus Christianorum. Continuatio Mediaevalis, 42), lib. 4, lín. 2991: His est rex Ludouicus, cuius pater Lodouicus usquequaque dilatauit regnum suum, et coiunxit ei in matrimonium filiam Guilelmi ducis Aquitaniam et comitis Pictauorum, propter quam acquisiuit omnem Aquitaniam, Guasconiam, Bascloniam et Nauarram usque ad montes Pyreneos et usque ad crucem Caroli.

9 Svgervs sancti Dionysi, Vita Ludouici, ed. Albert Lecoy de la Marche, Ouvres complètes de Suger, Paris, chez $\mathrm{M}^{\mathrm{me}}$. V $\mathrm{V}^{\mathrm{e}}$. Jules Renard, 1867, cap. 32: Cumque castrum Bestisiacum peruenisset, celeriter subsecuti sunt eum nuncii Guillelmi ducis Aquitaniae, denunciantes eundem ducem ad sanctum Iacobum peregre profectum in uia demigrasse, sed antequam iter aggrederetur, et etiam in itinere moriens, filiam nobilissimam puellam nomine Alienor desposandam totamque terram suam eidem retinendam et deliberasse et dimisisse. Qui communicato cum familiaribus consilio, solita magnanimitate gratanter oblata suscipiens, carissimo filio Ludouico eam copulari promittit.
} 
de Morigny, obra estupendamente informada de los eventos de su tiempo (11081147), le dio mayor cobertura a la muerte de Guillermo. Lo hace en términos semejantes a los de Sugero, al que conoce y del que depende en parte, pero ofreciendo también el punto de vista aquitano, poniendo la atención en el duque moribundo y afirmando que fue este, y no Luis $\mathrm{VI}^{10}$, quien dispuso el casamiento de Leonor con el príncipe Luis:

Sucedió que Guillermo, conde de Poitiers, después de partir en peregrinación a Santiago, se vio impedido por una grave enfermedad y puesto en trance de muerte. Al presentársele alli mismo el fatal momento dispuesto por Dios, y darse él cuenta de que era inminente el momento inevitable de exhalar el último aliento, hizo llamar a los próceres y prohombres de su tierra, y les conminó bajo juramento a que casaran a su hija con Luis [VII], el hijo del rey Luis [VI], y les entregaran a ambos sus territorios, en razón del matrimonio y conforme a la costumbre. Liberado de los afanes humanos, Guillermo fue enterrado en la misma Iglesia de Santiago ${ }^{11}$.

La Crónica de Morigny completa la noticia de la muerte del conde de Poitiers y duque de Aquitania con un dato muy relevante, del que Sugero se había desentendido: tras su muerte, Guillermo habría recibido sepultura en la Catedral de Santiago. Resulta al menos llamativo que el cadáver de un señor tan poderoso no fuera repatriado y enterrado en el panteón familiar de Saint-Jean de Montierneuf, fundado con enormes recursos por su abuelo Guillermo VIII con ese fin. Y más teniendo en cuenta que no había muerto solo, sino rodeado de los próceres de su tierra, a quienes había mandado llamar para encomendarles sus últimas voluntades. Sin embargo, la noticia que llegó a Francia, y de la que se hicieron eco no pocos autores, algunos de ellos muy allegados a Guillermo, fue que este murió como peregrino de Santiago y fue enterrado en la catedral compostelana.

\footnotetext{
${ }^{10}$ Este extremo se verifica en el Cronicón de los Condes de Poitiers, donde se transcribe a la letra el testamento de Guillermo, quien deja clara su voluntad de que Leonor sea entregada como esposa al hijo del rey francés: Filias meas regis domini mei protectioni relinquo, Leonoram collocandam cum Ludouico regis filio [...] Cfr. Chronica comitum Pictauiae, ed. Leopold Delisle [Ex fragmentis chronicorum comitum Pictaviae, ducum Aquitaniae, auctore ut uidetur, monacho S. Maxentii], Paris, Victor Palmé, 1887 (Rerum Gallicarum et Francicarum Scriptores. Nouvelle edition, 12), págs. 409-410.

${ }_{11}$ Chronica Mauriniacensis, ed. Léon Mirot, La Chronique de Morigny (1095-1152), Paris, Libraire de Alphonse Picard et fils, 1909, lib. 3, cap. 2: [...] contigit Guillelmum Pictauorum comitem ad sanctu Iacobum peregre profectionem aggresum, aspera infirmitate detineri et usque ad mortis difficultatis perduci. Hic itaque cum a Deo prouisa fatalis fili et ineuitabilem spiritus exalacionem sibi imminere conspiceret, terre sue proceres et optimates accersiens, eos coacticio iurisiurandi uinculo constrixit ut filiam suam Ludouico, regis Ludouici filio copularent, et terram suam ambobus secundum consuetudinem conubii manciparent. Ipse uero Guillelmus rebus humanis exentus, in eadem ecclesia beati Iacobi tumulatus est.
} 
Entre esos autores próximos al duque está el poeta en lengua provenzal Cercamón, quien le dedica un planh (planctus) cuyos versos finales son una plegaria a Santiago para que interceda por su peregrino ante él enterrado:

Ay, cómo lo llora el gascón, / el de España y el de Aragón.

Santiago, acuérdate del barón / que yace ante ti, peregrino ${ }^{12}$.

Otro autor que reúne las condiciones de contemporáneo y quizá allegado a Guillermo es el monje cluniacense Ricardo, oriundo del Poitou, por lo que es conocido indistintamente como Ricardo Cluniacense o Ricardo Pictavense. En su crónica universal, dedicada a Pedro el Venerable y por tanto anterior a 1156, Ricardo no se limita a la reseña cronística de la muerte del duque de Aquitania, sino que a esta le añade un planctus en 22 dísticos elegiacos, lamento ante la muerte del señor de su tierra ${ }^{13}$. Aparte de las efusiones expresivas propias del género y una semblanza algo convencional del finado, el poema presenta también una parte narrativa centrada en las circunstancias del fallecimiento del duque como pobre peregrino en tierra extranjera (occubuit peregre dux pauper in hospite terra), y de las modestas honras fúnebres que allí habría recibido ( $d u x$ miserande iaces paruo contentus honore). Pero además de esto, hay en él una frase (vv. 23-24) que podría estar reflejando el cogollo argumental del Romance de Don Gaiferos, donde el Apóstol se aparece al noble y le acompaña y asiste en los últimos pasos de su peregrinación. El grado de equivalencia entre los dos textos depende de lo que Ricardo quisiera expresar con el verbo principal de la oración, suscepit, pues este admite dos acepciones diferentes, las dos congruentes con el contexto y las dos igualmente válidas y usuales tanto en latín clásico como escolástico-medieval

\section{Dumque peregrinus Iacobi se reddit ad aram suscepit Iacobus corpore, post anima.}

Si lo interpretamos como 'acoger' ("Cuando el peregrino de Santiago se volvió hacia el altar / Santiago lo acogió en cuerpo, después en alma”), se entendería que el Apóstol se habría limitado a permitir que su peregrino recibiera

\footnotetext{
12 Cercamón, Poesies, ed. Alfred Jeanroy, Les poesies de Cercamon, Paris, Honoré Champion, 1922 (Classiques français du Moyen Age, 27), carm. 112.2a (Lo plaing comenz iradament), est. IX, v. 36: Ai! com lo plaigno li Gasco / cil d'Espaign'e e cil d'Arago / Sant Jacme, membre us del baro / que denant vos jai pelegris.

13 Richardvs Pictaviensis vel Clvniacensis, Chronica cum praefatione ad Petrum Venerabilem (planctus ad Guillelmum X ducem Aquitaniae), ed. Leopold Delisle, "Ex chronicone Richardi Pictavensis, monachi cluniacensis", en Rerum Gallicarum et Francicarum Scriptores. Nouvelle edition, vol. 12, Paris, Victor Palmé, 1887, págs. 413-414.
} 
entierro en su catedral, convirtiéndose después en su intercesor. Sin embargo, cabe aquí una segunda interpretación, 'sostener', y en este caso, la frase podría querer dar a entender que Santiago ayudó al peregrino que se dirigía a su altar, antes de interceder por su alma ("Cuando el peregrino de Santiago se dirigía hacia el altar / Santiago sostuvo su cuerpo, después su alma”). Deberá admitirse que aquí el grado de correspondencia con el Romance de Don Gaiferos, donde el protagonista es acompañado y asistido por el Apóstol en sus últimos pasos, es máximo.

Sea como fuere, el planctus de Ricardo, como el de Cercamón, son dos buenas muestras de cómo el suceso histórico dio lugar a sendas piezas literarias de ocasión. Esto debe ponerse en relación con la forma en la que este suceso ocurrido en Galicia viajó al otro lado de los Pirineos, porque en apariencia, y salvo estos dos casos, los testimonios que tenemos son de carácter estrictamente historiográfico. Sin embargo, en algunos de ellos, incluso en los escritos muy poco después de los hechos, se trasluce un tratamiento que no es estrictamente cronístico. No nos referimos a pequeñas divergencias sobre, por ejemplo, las circunstancias del testamento que cambian dependiendo de la fuente $^{14}$, sino a detalles que parecen contribuir a transformar los hechos relatados en materia literaria, aportándoles dramatismo, ejemplaridad o estructura. Por ejemplo, dependiendo de las versiones, Guillermo muere en algún momento indeterminado del viaje (Sugero, Cronicón de los Condes de Poitiers), o ya en Santiago de Compostela, lo que conlleva que sea enterrado en la misma catedral (Crónica de Saint-Maixent, Ricardo Pictavense, Cercamón, Orderico Vital). Independientemente de la fidelidad de cada una de las dos versiones a la realidad, habrá que convenir que la que sitúa la muerte en Santiago tiene más potencial “artístico". Según quien lo cuente, las exequias compostelanas del duque de Aquitania fueron sumamente modestas, como quiere Ricardo Pictavino (dux pauper, contentus paruo honore), o por el contrario, acordes a la dignidad del personaje, oficiadas por el propio arzobispo compostelano, según informa el Cronicón de Saint-Maixent.

A este [el duque Guillermo IX de Aquitania] le sucedió en el principado su hijo Guillermo X, que murió como peregrino en Santia-

\footnotetext{
${ }^{14}$ Por ejemplo, la Chronica Mauriniacensis (lib. 3, cap. 2) informa de que Guillermo hizo testamento solamente cuando ya estaba en trance de muerte, es decir, en plena peregrinación o a punto de cumplirla, mientras la Chronica comitum Pictauiae (págs. 409-410) sostiene que el duque lo hizo antes de emprender el camino previendo que, enfermo como estaba, iba morir en el mismo, como así sucedió. Por su parte, Sugero (Vita Ludouici, cap. 32) concilia estas dos versiones al afirmar que en realidad hubo dos momentos testamentarios, donde el segundo habría servido para refrendar el primero, y hacer jurar a los barones aquitanos que respetarían la voluntad de su príncipe.
} 
go, en España. Fue también sepultado de forma solemne por el arzobispo de allí en la misma iglesia del apóstol, en la que falleció ${ }^{15}$.

Por cierto, este texto también presenta una concordancia significativa con el Romance de don Gaiferos, donde el obispo compostelano también comparece como testigo de la muerte del duque y como responsable de su enterramiento en el santuario (o bispo que esto mirou / alí o mandou enterrar). En cualquier caso, la modestia o solemnidad del funeral están estrechamente relacionadas con la fecha de su muerte, según las fuentes contemporáneas que mencionan este extremo. Según el Cronicón de Saint-Maixent, Ricardo Pictavense u Orderico Vital, esta tuvo lugar el 9 de abril. En esta fecha, que es perfectamente verosímil a juzgar por las otras involucradas en esta historia, cayó el Viernes Santo del año $1137^{16}$. No hay que descartar de ninguna manera, más bien todo lo contrario, que Guillermo hubiera programado su viaje para que la llegada a Santiago coincidiera con esta fecha, constando como consta que el objetivo de su peregrinación era exclusivamente penitencial. Además de testimonios más o menos cercanos como el Cronicón de los condes de Poitiers u Orderico Vital, es el propio Guillermo quien nos confirma su disposición de ánimo a la hora de emprender el viaje, con estas elocuentes expresiones que forman la parte central de su testamento:

[...] Después de echar la cuenta de los innumerables pecados que por persuasión del diablo cometí de forma temeraria; de llenarme de temor ante el día del juicio tremendo; de comprender que las riquezas que en apariencia poseemos, en realidad son como humo que se desvanece en nuestras manos; y de reconocer que yo mismo no fui capaz de pasar una sola hora sin pecar durante mi paso por el mundo, a pesar de saber lo poco que en él permanecemos y de que todo aquello que creemos poseer no son sino cosas caducas y lastre para sus dueños. Por todo ello, me encomiendo a Dios, a quien quiero seguir dejando todo lo demás $[. . .]^{17}$.

\footnotetext{
15 Chronica sancti Maxentii, ed. Leopold Delisle [Ex chronico sancti Maxentii quod uulgo Malleacense dicitur], Paris, Victor Palmé, 1887 (Rerum Gallicarum et Francicarum Scriptores. Nouvelle edition, 12), pág. 408: Cui succesit in principatu Guillelmus filius eius, qui obit peregrinus apud sanctu Iacobum in Hispania. Est quoque sepultus in ecclesia eiusdem apostoli in qua obiit, honorifice ab archiepiscopo loci illius.

${ }^{16}$ Augusto CAPPELl, Cronologia, cronografia e calendario perpetuo: dal principio dell'Era Cristiana ai nostri giorni, quinta edizione aggiornata, Milano, Ulrico Hoepli, 1983, pág. 76.

${ }_{17}$ Chronica comitum Pictauiae, págs. 409-410: [...] Cogitans de meis innumerabilis peccatis quae suadente diabolo temerarie perpetraui, et timens tremendi iudicii diem, uidens bona quae uidemur tenere sicut fumum in aere inter manus nostras euanescere, nosmet etiam in hac peregrinatione sine peccato una
} 
A juzgar por estas palabras, resulta claro que Guillermo de Aquitania era consciente de que podía morir en esa peregrinación. En ese caso, desde el punto de vista de un penitente sinceramente arrepentido, ¿qué mejor momento que después de haberse mortificado con un duro peregrinaje hasta la sede de un apóstol de Cristo, en la fecha más adecuada del año para mostrar el dolor por los pecados e implorar la misericordia divina? Nada se opone a que las cosas sucedieran realmente así, pero hay que reconocer que la fecha del Viernes Santo confiere mayor dimensión poética a un acontecimiento ya suficientemente adobado con ingredientes que lo convertían en una historia digna de ser contada: el arrepentimiento de uno de los personajes más poderosos de su tiempo, famoso por sus violencias y desmesuras ${ }^{18}$; la penitencia extraordinaria de marchar a Santiago con el hábito de peregrino y posiblemente ya enfermo; y la redención final, en forma de una muerte rodeada de piedad, precisamente en el día en que se garantizaba a los penitentes indulgencia plenaria por sus pecados. Por si fuera poco, esto sucedía en el santuario peregrinal por antonomasia, Santiago de Compostela, en un tiempo en el que las peregrinaciones adquieren, entre otras cosas, su dimensión penitencial $^{19}$, y en el que sería el segundo año jubilar compostelano de ser cierta la tradición que atribuye su institución al papa Calixto $\mathrm{II}^{20}$. Uno de los autores que

hora non posse uiuere et satis paruo tempore manere, et omnia quae putamus possidere esse caduca et suis possesoribus gravamen, commendo me Deo quem relictis omnibus sequi uolo [...].

${ }_{18}$ Aparte de las malas acciones cometidas en Normandía y recordadas por Orderico Vital (cfr. n. 21), Guillermo $\mathrm{X}$ es conocido por varios episodios poco edificantes, entre los que destacan sus violencias contra el clero de Poitiers o su apoyo al antipapa Anacleto II. Es particularmente famoso, por sus recreaciones iconográficas posteriores, su enfrentamiento y humillación ante san Bernardo de Claraval, que supuso su reconciliación con la Iglesia. Cfr. Arnaldvs BonaEvallensis, Vita I Bernardi, ed. Jean Mabillon, en Patrologia Latina, vol. 185, cols. 289-290 (localización precisa del pasaje dentro del vol. 185 de la PL. cols. = columnas), Paris, Jean-Paul Migne, 1860, lib. 2, cap. 6.

${ }_{19}$ Sobre cómo precisamente en este tiempo las peregrinaciones cristianas se transforman, desde el punto de vista conceptual y material, en lo que hoy entendemos por ellas, incluyendo el componente esencial de la penitencia, cfr. José M. a ANGUITA JAÉN, "Peregrinatio: la conformación de un concepto, la transformación de una realidad”, en Santiago López Martínez-Morás, Marina Meléndez Cabo, Gerardo Pérez Barcala (coords.), Identidad europea e intercambios culturales en el Camino de Santiago (siglos X-XV), Santiago de Compostela, Universidad de Santiago de Compostela, 2013, págs. 151-168.

${ }^{20}$ Según la conocida regla de la coincidencia de la fiesta en domingo (cfr. CAPPELLi, Cronologia..., pág. 77), este habría sido el segundo año jubilar, mientras que a 1126 le habría cabido el honor de ser el primero, como quizá indique la famosa referencia temporal de la coronación de Alfonso VII, en "el tiempo bendito del año jubilar” [Chronica Adefonsi Imperatoris, ed. Antonio Maya Sánchez, Chronica hispana saeculi XII. Pars I, Turnhout, Brepols, 1990 (Corpus Christianorum. Continuatio Mediaevalis, 71), lib. 1, cap. 1: beato iubilei anni tempore]. Se ha discutido mucho sobre la existencia real de estos primeros años santos apenas documentados. La falsedad obvia de la bula Aeterni regis de Alejandro III (presuntamente 1179-1181), que confirmaría otra perdida de Calixto II, parece inclinar la balanza a favor de una institución tardía (s. XV) de los años santos compostelanos. Sin embargo, la alusión de la Crónica de Alfonso el Emperador y la propia peregrinación, de talante tan marcadamente penitencial de Guillermo de Aquitania, podrían esgrimirse como argumentos a tener en cuenta a favor de un precedente antiguo, quizá en estado solamente embrionario, de la institución jubilar compostelana. 
mencionan la fecha, Orderico Vital, nos ofrece un microrrelato perfectamente ajustado a la ejemplarizante secuencia pecado-penitencia-redención:

Guillermo, duque del Poitou, con la mente en las malas acciones que había cometido recientemente en Normandía y movido por el deseo de penitenciarse, salió como peregrino rumbo a Santiago. Después, en el Viernes de la Semana Santa, 9 de abril, confortado con la santa comunión, falleció devotamente delante del altar del bienaventurado apóstol ${ }^{21}$.

Ricardo Pictavense, por su parte, en consonancia con el tono panegírico de su planctus, omite también en la prosa aludir a los pecados del duque, con lo que resta un componente esencial al relato de su muerte. Sin embargo, le añade a este un efecto dramático extraordinario, desconocido en el resto de narraciones: Guillermo no habría expirado en un momento cualquiera del Viernes Santo, sino en el punto central de la liturgia de ese día, en medio de la lectura de la Pasión:

Guillermo, duque de Aquitania [...], en el año 1137 de la Encarnación del Señor viajó como peregrino al sepulcro de Santiago en España; y allí, en la misma iglesia, delante del altar, confortado con la extremaunción entregó su alma el Viernes Santo mientras se leía la pasión de Cristo ${ }^{22}$.

En conclusión, la muerte en Compostela del décimo duque de Aquitania, suceso de cuya historicidad no cabe dudar, parece haber sido manipulada con fines artísticos ya en su tiempo, lo que se verifica, como cabría esperar, en los panegíricos fúnebres de sus allegados, pero también se trasluce en algunos de los relatos cronísticos que la refieren. Como acabamos de ver, esta historia real contenía todos los ingredientes necesarios para convertirse en muy buen material literario. Algunos de estos (el acompañamiento del peregrino por el Apóstol, el entierro por el Arzobispo) se encuentran también en el Romance de Don Gaiferos, mientras que otros, quizá los más espectaculares (la muerte en Viernes Santo en el momento central de la liturgia), no comparecen en el mismo, lo que parece

\footnotetext{
${ }^{21}$ Ordericvs Vitalis, Ecclesiastica historia, ed. André Du Chesne, Orderici Vitalis Ecclesiastica historia, en Patrologia Latina, vol. 188, Paris, Jean-Paul Migne, 1855, lib. 3, cap. 13: Guillelmus, Pictauensium dux, memor malorum quae nuper in Normannia operatus est, poenitentia motus ad sanctum Iacobum peregre profectus est. Deinde feria VI Parasceue, Vidus aprilis, sacra communione munitus est et ante aram Beati Apostoli uenerabiliter defunctus est.

22 Richardvs Pictaviensis vel Clvniacensis, Chronica cum praefatione ad Petrum Venerabilem, pág. 413: Willelmus itaque Dux Aquitanorum [...] anno ab Incarnatione Domini MCXXXVII dum in Hispaniam ad sanctum Iacobus limina orationis gratia pergeret, in eiusdem ecclesia ante altare die sancto parasceue, dum Christi passio legeretur, uiatico sancto munitus reddidit animam.
} 
sugerir una transmisión que se ha dejado por el camino una buena cantidad de materiales. Y que ha incorporado una chocante novedad, la de cambiar el nombre real del protagonista, Guillermo, por el de Gaiferos. Si el cambio de nombre se produjo, como pensamos, en época temprana o incluso contemporánea de los hechos, esto explicaría la clamorosa inexistencia de testimonios compostelanos, y por extensión, hispanos, de un acontecimiento de tanta relevancia y espectacularidad. Efectivamente, sabemos que la muerte de Guillermo X de Aquitania no dio lugar nunca a una tradición local, no tanto porque la Historia Compostelana o el Liber sancti Iacobi, que no se ocupan en la reseña de peregrinos ilustres, no la aludan en ningún momento, como porque en la historiografía hispana nadie muestra saber nada del asunto hasta el s. XVI, cuando Zurita y Mariana lo mencionan por primera vez, en dependencia visible de fuentes historiográficas francesas ${ }^{23}$. A partir de estas obras bien conocidas, o de los bolandistas a partir del s. XVII, un dato tan llamativo en relación con la diócesis sí que pudo ser conocido por los eruditos compostelanos, aunque lo cierto es que no nos constan testimonios anteriores al s. XIX ${ }^{24}$. De hecho, es Murguía el primero que habla de él al justificar su identificación de Gaiferos con Guillermo:

\section{Era tradición en la iglesia que un Guillermo, duque de Aquita- nia, visitó Santiago, y que al llegar ante el altar del Apóstol, cayó muerto de repente, siendo enterrado en nuestra iglesia ${ }^{25}$.}

Lógicamente, por lo que acabamos de ver, no se refiere a una tradición de la iglesia local compostelana, sino a la amparada por los bolandistas, hagiógrafos oficiales de la Iglesia católica, tal como se puede leer en la nota a que reenvía el comentario anterior:

De dos de estos duques se sabe que visitaron Santiago, Guillermo
V en el siglo XI (venía todos lo años), y en el siglo XII Guillermo
X, último duque de Aquitania, gran amigo de D. Diego Gelmírez.

\footnotetext{
${ }^{23}$ Zurita cita explícitamente a Vicente de Beauvais y Bernardo Gui como sus fuentes, mientras que Mariana menciona la peregrinación de Guillermo junto con todos los hechos importantes para la historia de Francia a que dio lugar su muerte (matrimonio y divorcio de Leonor y Luis VII, matrimonio de Leonor con Enrique II, creación del imperio angevino, guerras anglo-francesas...). Cfr. Jerónimo ZURITA, Anales de la Corona de Aragón, Zaragoza, casa de Pedro Bernuz, 1562, vol. 1, libr. 1, fol. 34; Juan de MARIANA, Historiae de rebus Hispaniae libri XXX, Moguntia, Impensis Danielis ac Dauidis Aubriorum et Clementis Schleichii, 1619, vol. 1, lib. 10, cap. 15, pág. 437.

${ }^{24}$ No deja de sorprender la escasa atención recibida por la muerte del duque de Aquitania entre los historiadores de la iglesia compostelana. Todavía en 1901, López Ferreiro, le consagraba solamente el espacio de una nota de dos líneas en sus voluminosos once volúmenes de historia compostelana. Cfr. Antonio López Ferreiro, Historia de la Santa A.M. Iglesia de Santiago de Compostela, Santiago de Compostela, Seminario Conciliar Central, 1901, vol. 4, pág. 31, n. 1.

${ }^{25}$ Murguía, Galicia, pág. 423.
} 
Á éste es a quien debe referirse el romance, pues de él se cuenta que vino á pie en traje de peregrino el año de 1137, y que al final de su viaje murió delante del altar de Santiago Apóstol el día de Viernes Santo. Esta leyenda, aunque amparada por los Bolandistas y Longueval, no parece cierta si se ha de creer lo que dice Lacolonie, y recuerda Pardiac, p. 143 de su Pélerinage, etc. Puede por lo tanto suponerse que el romance es posterior á los Bolandos, pues se muestra conforme en todo con lo escrito por estos padres. El soldado que habla con el viejo peregrino y le conforta, acompañándole hasta Santiago, no es otro que el mismo Apóstol. El hallar á Guillermo X convertido en Gaiferos, nos dice que si el fondo del romance es eclesiástico, se debe sin embargo á un poeta popular que mezcla con la leyenda religiosa los recuerdos caballerescos ${ }^{26}$.

La nota nos muestra, en realidad, que Murguía tiene noticia de la peregrinación y muerte de Guillermo X exclusivamente gracias a la obra de Pardiac, al que cita puntual y correctamente ${ }^{27}$. Los otros autores a los que menciona, Longueval $^{28}$, los Bolandistas ${ }^{29}$ y Lacolonie ${ }^{30}$, le son conocidos solamente de forma indirecta, precisamente a través de Pardiac. El hecho de depender exclusivamente de este estudioso, y de conocer a los otros solo a partir de los resúmenes de este, indujo a Murguía a decantarse por una teoría extraña, sostenida por Lacolonie, según la cual la muerte compostelana de Guillermo X no era más que un bulo historiográfico propalado por la autoridad de los prestigiosos hagiógrafos jesuitas $^{31}$. Esto explica su deducción, en principio extraña, de que el romance

\footnotetext{
${ }^{26}$ Murguía, Galicia, pág. 423, n. 1.

${ }_{27}$ Jean-Baptiste PARDIAC, Histoire de S. Jacques le Majeur et du pèlerinage a Compostelle, Bordeaux, L. Coderc et $\mathrm{C}^{\text {ie }}, 1863$, págs. 143-144.

28 Jacques Longueval, Histoire de l'Eglise Gallicane, Paris, Montalant-Coignard-Guerin-Rollin, 1734, vol. 8, págs. 582-583.

29 Willem CuYPer [Guillelmus Cuper], "Sanctus Iacobus Maior" [Iul.VI, dies 25], en Acta Sanctorum Bollandistarum, Amberes, apud Iacobum du Moulin, 1729, vol. 6, col. 34A.

30 Jean-Martin de LACOLONIE, Histoire curieuse et remarquable de la ville et province de Bordeaux, Bruxelles, aux dépens de la Compagnie, 1760, vol. 1, págs. 161-179.

31 En realidad, los Bolandistas habían reunido y comentado las fuentes contemporáneas de los acontecimientos con el fin de deshacer el embrollo biográfico que confundía la figura de Guillermo X de Aquitania con distintos santos del mismo nombre (su antepasado Guillermo de Aquitania, Guillermo de Vercelli y, especialmente, Guillermo Magno), dejando prácticamente probada la historicidad de la muerte compostelana de Guillermo X. Cfr. Godfried Henschen, "Sanctus Guillelmus Eremita apud Stabulum Rodis in Etruria” [1Feb. II, dies 10], Acta Sanctorum Bollandistarum, Amberes, 1658, vol. 2, cols. 441D-443A, especialmente el epígrafe dedicado a las fuentes de la muerte compostelana de Guillermo X (Consensus historicorum seculo Christi XII, XIII et XIV de eadem ducis Guilielmi apud Compostellam morte). Por el contrario, el cronista bordelés Lacolonie se había abonado a un enredo novelesco propiciado precisamen-
} 
solo haya podido ser compuesto a partir del s. XVII. Extraña porque contradice abiertamente la posibilidad, sostenida poco más arriba, de que pudiera ser una supervivencia medieval.

En cualquier caso, una vez establecida la relación del argumento del Romance de don Gaiferos con la historia real de Guillermo X de Aquitania, mérito de Murguía, al erudito le quedaba por explicar el sinsentido de que una figura histórica del relieve del último duque de Aquitania aparezca en el romance disfrazada bajo la máscara literaria de Gaiferos. Lo explica como el resultado de la actuación de un juglar que habría mezclado el fondo eclesiástico del poema con "recuerdos caballerescos". En su opinión, el extraño cambio de nombre se debería únicamente a la contaminación de dos tradiciones independientes entre sí. En el punto siguiente, trataremos sobre esos recuerdos caballerescos a los que se refiere Murguía, y sobre el entramado de relaciones que permiten vincularlos al personaje de Guillermo X.

\section{Gaiferos y Aquitania}

Gaiferos es la forma castellana - bien conocida por el protagonista de algunos romances viejos, atestiguados desde el s. $\mathrm{XVI}^{32}$ - del nombre de un personaje literario de antigua y compleja genealogía. Las dudas de falsedad que se ciernen sobre el romance gallego, así como la discordancia de su argumento jacobeo con la peripecia caballeresca cantada en esos romances viejos, ha hecho que la posibilidad de un origen común para Gaiferos de Mormaltán y el Gaiferos (Gaiferes, Caiferes, Galfeiros) del romancero panhispánico ni siquiera se haya planteado. Lo cierto es que sí existen elementos que permiten establecer vínculos entre uno y otro, aunque antes de abordar esta cuestión, será preciso detenerse durante unos párrafos en la figura del Gaiferos de los romances viejos y el proceso que explica los materiales literarios a él asociados, caracterizados por su complejidad.

El punto de partida de Gaiferos, señalado por la propia onomástica, está en un personaje histórico conocido como Waifarius (Waifre, Waiofar), señor de Aquitania una generación antes de Carlomagno, conocido por su enfrentamiento con el padre de este, Pipino de Heristal, quien terminó derrotándolo en una larga campaña que concluyó con su muerte $(\dagger 765)$ y la pérdida de la autonomía aqui-

\footnotetext{
te por la confusión temprana de estos personajes, según el cual el duque de Aquitania habría fingido su muerte en Compostela para continuar sus peregrinaciones de incógnito, primero a Roma, después a Tierra Santa, donde habría muerto en 1157 (es decir, la fecha y la circunstancia de la muerte de san Guillemo Magno). Cfr. Lacolonie, Histoire curieuse..., vol. 1, págs. 161-179.

${ }^{32}$ Inmortalizada, podría decirse, por su aparición en el Quijote ( $2^{\mathrm{a}}$ parte, cap. 26), donde la caballeresca historia de Gaiferos es representada por unos titiriteros en el famoso episodio del retablo de Maese Pedro.
} 
tana, según refieren las fuentes contemporáneas ${ }^{33}$. A partir del s. XI, podemos comprobar cómo este Waifarius histórico se ha convertido ya en figura literaria, le riche duc Gaifiers o Gaifiers [rois] de Bordel, presente en una larga serie de chansons y obras afines escritas en Francia durante la Edad Media ${ }^{34}$. En estas obras, el antiguo enemigo de Pipino aparece convertido en coetáneo y aliado de Carlomagno, figurando incluso entre los guerreros de la hueste de Roldán muertos en Roncesvalles. Aparte de esta importante transformación, las señas de identidad que definen a Gaifiers, su gran riqueza ${ }^{35}$, su dignidad señorial y su origen aquitano ${ }^{36}$, parecen deudoras del histórico Waifarius.

En todo caso, y a pesar de ser un personaje asiduo de los cantares épicos franceses, Gaifiers es en ellos un "extra" sin más atributos que los recién reseñados. Curiosamente, la biografía de Gaifiers desconocida por la épica francesa medieval conservada, nos la refieren, al menos parcialmente, varios romances viejos españoles, donde el antiguo héroe, llamado ya Gaiferos, presenta una caracterización y una peripecia nueva, ajena al Waifarius histórico y desconocida en el Gaifiers de las chansons. Aunque la materia del Gaiferos hispano se divide en dos grandes apartados argumentales, la crítica ha centrado su atención especialmente en uno de ellos, representado por una larga y variada muestra de piezas, la mayor parte orales ${ }^{37}$, otras escritas, entre las que destaca el romance viejo que comienza con las palabras Assentado está Gayferos, el testimonio más

\footnotetext{
${ }^{33}$ Fredegarivs, Chronica, ed. Bruno Krusch, Chronicarum quae dicuntur Fredegarii Scholastici libri IV cum continuationibus, Hannover, Hahn, 1888 (Monumenta Germaniae Historica, Scriptores Rerum Merovingicarum, 2), caps. 124-135.

${ }^{34}$ Para el catálogo de obras en las que aparece Gaiferos, cfr. André MoIsAN, Répertorie des noms propes de personnes et de lieux cités dans les chansons de geste françaises et les ouvres étrangères derivées, $\mathrm{t}$. I, vol. 1, Droz, Généve, 1986, págs. 439-440.

${ }^{35}$ Estas riquezas proverbiales están simbolizadas en los conocidos brazaletes de oro (les bous Gaiffier) que, tras acabar con Waifarius, Pipino depositó en Saint-Denis, donde aún se podían ver en el tiempo en que se redactaron las Grandes Crónicas de Francia (s. XIII). Cfr. Chroniques de Saint-Denis, ed. Pauline Paris, Les grandes chroniques de France selon que elles sont conservées en l'eglise de Saint-Denis, Paris, Techener, 1836-1838, vol. 2, pág. 52.

${ }^{36}$ En la manera en que lo designa la crónica del Pseudo-Turpín (Gayferus rex burdegalensis) se refleja bien tanto su dignidad real como su vinculación a Burdeos, donde fue, además, enterrado tras su muerte. Cfr. Liber sancti Iacobi, ed. Klaus Herbers y Manuel Santos Noia, Liber sancti Iacobi. Codex Calixtinus, Santiago de Compostela, Xunta de Galicia, 1999, lib. 4, caps. 11 y 29.

${ }^{37}$ Hay una serie de piezas recogidas, ya en el s. XX, como tradición oral de distintos lugares de España y Portugal (Galfeiros) o entre las comunidades sefardíes. Además, el argumento de la historia de Gaiferos aparece protagonizado por personajes con otro nombre (petit Jean, Jean de Florence, Pierre de Florence, Pierre de Provence, lo comte pelegri...) en poemas tradicionales recogidos en Cataluña, Francia e Italia, y reunidos bajo el nombre de Escriveta, su protagonista femenina en muchos de los recogidos en Cataluña. Para la catalogación y una edición selecta de los romances panhispanos (castellanos, portugueses, sefardíes), cfr. Víctor Millet, Waltharius-Gaiferos: über den Ursprung der Walthersage und ihre Beziehung zur Romanze von Gaiferos und zur Ballade von Escriveta, Frankfurt et al., Peter Lang, 1992, págs. 242319 (textos), 153-168 (catalogación). Para los poemas recogidos en ámbito catalán, occitano, italiano, del grupo Escriveta, cfr. págs. 320-344 (textos), 168-194 (catalogación).
} 
extenso y rico en detalles ${ }^{38}$. La razón principal de esta atención se debe a sus sugestivas concordancias argumentales con el Waltharius, un epos latino salido en el s. X del scriptorium de San Galo, reflejo de materiales mucho más antiguos relacionados con la primitiva épica germánica. El cómo, el cuándo y el dónde se fundieron los motivos de Waltharius y del Gaifiers ya carolingizado es una apasionante y compleja cuestión que, tras un siglo de debate filológico, sigue aún viva ${ }^{39}$. Sin que se pueda dar por concluida a estas alturas, diversos indicios puestos de manifiesto recientemente apuntan a que esto debió ocurrir durante el s. XI en la región de Aquitania, de donde habría pasado a España posteriormente, para dar cuerpo a los romances sobre Gaiferos ${ }^{40}$. Uno de los apoyos más sólidos de esta teoría se encuentra en una epístola métrica latina escrita hacia 1100 por Rodolfo Tortario de Fleury, primer registro del Amis et Amiles, donde encontramos engarzadas las materias de Walter y Gaiferos, por medio de la coexistencia de motivos ${ }^{41}$. Además, se ha puesto también cierto énfasis en la transmisión manuscrita del Waltharius, estrechamente relacionada con Fleury $\mathrm{y}$, a través de este, con la región sud-occidental francesa, a través del priorato floriacense de La Reole, uno de los monasterios más importantes de Gascuña ${ }^{42}$. Sin despreciar este dato, nos parece más reseñable que el Amicus et Amelius de Tortario, cuya acción -frente a la del Amis et Amiles que sucede en la corte de Carlomagno- se desarrolla en la corte del rey Gaiferos, nos muestre un reflejo de la realidad política del ducado aquitano en el s. XI. Esto se consigue de una forma muy económica, mediante una breve lista de los dominios de Gaiferos (v. 132: Pictonus Aruernus Vascoque seruit huic), que se inicia con el etnónimo de la región preponderante y sede señorial, el Poitou, y sigue con los de sus vasallos Amico y Amelio, Aubernia y Gascuña.

\footnotetext{
${ }^{38}$ Cfr. Cancionero de romances, ed. Antonio Rodríguez Moñino, Madrid, Castalia, 1967, fol. 148. Se trata también del más célebre, a juzgar por su difusión editorial en colecciones (cancioneros, silvas) como la que citamos, y en pliegos sueltos impresos a partir del s. XVI. Para el catálogo de su presencia en pliegos sueltos, cfr. Antonio RodrígueZ-MoÑIno, Diccionario bibliográfico de pliegos sueltos poéticos (siglo XVI), Madrid, Castalia, 1970, núms. 991-1001. Para su presencia en colecciones, cfr. Antonio RodríGueZ-MoÑIno, Manual bibliográfico de cancioneros y romanceros, Madrid, Castalia, 1973-1978, núms. I, 51 (52-61); 86 (87); 98 (99-131): III, 231 (20, 232-243).

${ }^{39}$ Para un resumen de la larga e intrincada discusión filológica a la que ha dado lugar este asunto, cfr. Millet, Waltharius..., págs. 100-123. Para una última actualización de la misma, cfr. Gustav Adolf BECKMANN, Gualter del Hum-Gaiferos-Waltharius, Göttingen, De Gruyter, 2010, págs. 53-90.

${ }^{40}$ Cfr. Beckmann, Gualter del Hum..., págs. 75-85.

${ }^{41}$ Rodvlphvs Tortarivs, Epistula II ad Bernardum, ed. Marbury B. Ogle y Dorothy M. Schullian, Rodulfi Tortarii Carmina, Roma, American Academy in Rome, 1933, vv. 120-340, págs. 256-267. Los motivos del Waltharius y de Gaiferos coexistentes en esta obra son, por una parte, la espada rota en pleno combate, tomada del Waltharius (ed. Karl Strecker, Weimar, Böhlaus, 1951, vv. 1369-1375); por otra, el de la espada invencible que la substituye, perteneciente a Roldán, común con los romances de Gaiferos. Aparte de esto, el rex Gaferius de la epístola de Rodolfo Tortario es, como en los romances, yerno de Carlomagno.

42 Beckmann, Gualter del Hum..., pág. 77.
} 
Pero aparte de la Epístola de Rodolfo Tortario, hay otros indicadores que apuntan a Aquitania, y más concretamente a Poitiers, como el lugar donde no solamente se fusionaron las materias de Walter y Gaifiers, sino también como el lugar donde se incorporaron sustanciosas novedades que contribuyeron a configurar el proto-Gaiferos conocido por los romances españoles. Porque, por sugestiva y apasionante que pueda resultar la presencia de una materia tan antigua como la de Walter en los romances del s. XV, esta solamente constituye una pequeña parte en la historia de Gaiferos, cuyo desarrollo presenta evidentes diferencias respecto a la de Walter: en un caso se trata de la huída de unos rehenes, Walter y su prometida Hildegunda, de la corte de Atila. En otro, Gaiferos tiene que viajar desde Francia hasta una ciudad llamada Sansueña para rescatar del cautiverio a su esposa Melisendra.

Como veremos en el último punto de este trabajo, Guillermo X de Aquitania (reg. 1126-1137) pudo haber sido conocido por el sobrenombre de Gaiferos. Sin embargo, parece que ya durante el s. XI se había venido produciendo una asimilación progresiva de la figura literaria de este nombre con los señores aquitanos de este tiempo. Este proceso, que se refleja, como acabamos de ver, en la epístola de Tortario de 1100, habría sido en doble sentido, de modo que los duques de Aquitania del s. XI no solo habrían sufrido una asimilación pasiva al antiguo héroe local, sino que también habrían aportado rasgos propios al personaje literario que se estaba configurando en su tiempo. En ese sentido, un aspecto que nos parece fundamental en la peripecia de Gaiferos es que esta se desarrolla en un paisaje literario sin localización geográfica precisa, pero que el lector ubica con naturalidad en la España musulmana, como veremos más adelante. Sin duda, esto tiene mucho que ver con los estrechos vínculos que los duques aquitanos del s. XI establecieron con los reinos cristianos peninsulares, hecho que sin duda fue decisivo a la hora de atraer el interés hacia España de juglares e intelectuales vinculados con la corte literaria de Poitiers, en cuyos entornos se fusionaron viejos materiales literarios como los del Waltharius con las novedades surgidas en este siglo. Y no sería descabellado pensar que algunas de esas novedades procedieran de las expediciones guerreras comandadas en España por los duques Guillermo VIII o Guillermo IX ${ }^{43}$, o de los matrimonios de princesas de la casa de Poitou con reyes de León o Aragón ${ }^{44}$, sin olvidar las peregrinaciones a Santiago de Compostela de Guillermo V, Guillermo IX o Guillermo X. Bajo nuestro

\footnotetext{
${ }^{43}$ La más señalada por su trascendencia fue la cruzada de Barbastro de 1063, que tuvo uno de sus capitanes en Guillermo VIII. Su sucesor, Guillermo IX el Trobador participó junto a su cuñado Alfonso I de Aragón en la también decisiva batalla de Cutanda (1120).

${ }_{44}$ Dos hijas de Guillermo VIII, las dos de nombre Inés, casaron con Alfonso VI de León y Pedro I de Aragón. Una generación posterior, una hija de Guillermo IX, otra Inés, casó con el sucesor de Alfonso I de Aragón, Ramiro II el Monje.
} 
punto de vista, las aventuras de los duques aquitanos en la península al frente de sus poderosas mesnadas, y también la presencia de princesas pictavinas en las cortes hispanas, pudieron servir de inspiración a los juglares involucrados en el desarrollo de Gaiferos y, desde luego, para activar el papel de la Península Ibérica como escenario literario de las hazañas caballerescas del héroe.

El tema del rescate de Melisendra por su esposo Gaiferos tras largos años de cautiverio en tierra infiel está muy cerca - diríamos que casi contaminado con éldel tópos de la princesa mora que se enamora de un príncipe cristiano y escapa con él. No responde este, que sepamos, a ninguna historia protagonizada por princesas o príncipes aquitanos, pero sí por alguien estrechamente emparentado con ellos, Alfonso VI. Se trata de su poética, y aún así histórica, relación con la nuera de Al-Mutamid de Sevilla, Zaida, que dio lugar a una tradición literaria oral, cuyo reflejo se nos muestra en crónicas como la de Jiménez de Rada ${ }^{45}$, y cuyo éxito podemos calibrar por haber servido de inspiración a cantares franceses como el Mainet, donde un juvenil Carlomagno asume el protagonismo de la historia, o la Chanson de Saïsnes, contextualizada en la conquista de Sajonia. Muestra del entrelazamiento contaminado de estas historias es el hecho de que sea precisamente Saxonia (Saisogne, Seissogne, Sansoigne) ${ }^{46}$ el origen del llamativo topónimo literario de Sansueña, la ciudad musulmana que sirve de cautiverio a Melisendra en el Assentado está Gaiferos, y relacionada siempre, de algún modo, con las protagonistas femeninas de estas historias y sus distintas variantes ${ }^{47}$. El apasionante y no resuelto tema de Sansueña creemos que podría

\footnotetext{
${ }^{45}$ Rodericvs Ximenez de Rada, Historia de rebus Hispanie siue Historia Gothica, ed. Juan Fernández Valverde, Opera omnia I, Turnhout, Brepols 1987 (Corpus Christianorum. Continuatio Mediaevalis, 72), lib. 6, cap. 30. Respecto a la naturaleza de esa tradición oral, y los fundamentos para la existencia o negación de un hipotético Cantar de la mora Zaida, cfr. Ramón MenÉndez Pidal, La España del Cid, Madrid, Espasa-Calpe, 1969, vol. 1, págs. 405-406 y vol. 2, págs. 762-765; y Alberto MonTANER FruTOS, "La mora Zaida, entre historia y leyenda (con una reflexión sobre la técnica historiográfica alfonsí", en Barry Taylor y Geoffrey West (eds.), Historicist Essays on Hispano-Medieval Narrative. In Memory of Roger M. Walker, London, Maney Publishing, 2005, págs. 272-352.

${ }^{46}$ Cfr. Moisan, Répertoire..., vol. 2, págs. 1391-1392 y 1394.

47 En la Chanson des Saisnes [ed. Anette Péry Brasseur, Genève, Droz, 1989 (Textes littéraires français, 369), passim], la viuda de Guiteclin y, por tanto, reina de Sajonia, recibe el nombre de Sebile (cfr. Isabel, nombre de bautismo de Zaida, o Sevilla, taifa de su suegro Mutamid). Aunque en el Mainet [ed. Gaston Paris, "Mainet, fragments d'une chanson de geste du XII' siècle", Romania, 4 (1875), págs. 305-337, fr. IIIa, vv. 2, 15, etc.] la hija de Galafre de Toledo se llama Galiene, en el resumen que se hace de esta obra en la llamada Crónica fragmentaria, la princesa recibe el doble nombre de Sibilia Galiana [cfr. Inés FERnÁNDEZ ORDóÑEZ, "El tema épico-legendario de Carlos-Mainete y la transformación de la historiografía medieval hispánica entre los siglos XIII y XIV”, en Jean-Philippe Genet (coord.), L'histoire et les nouveaux publics dans l'Europe médiévale (XIIIe-XIVe siècles). Actes du colloque International organisé par la Fondation Européene de la Science á la Casa Velasquez, Madrid, 23-24 avril 1993, Paris, Publications de la Sorbonne, págs. 89-112]. Y en la variante de esta historia inserta en la vita latina de San Honorato, Sibila es hija del rey Almanzor de Toledo y regina Saxonie (cfr. Vita sancti Honorati, ed. Bernhard Munke, Halle, Ehrhardt Karras, 1911, pág. 54). Recordemos que en el Assentado está Gayferos,
} 
encontrar una de sus claves en este contexto de relaciones hispano-aquitanas de los siglos XI y XII" ${ }^{48}$.

En cualquier caso, la cabalgada a Sansueña no es el único episodio de Gaiferos presente en el romancero viejo. Dos piezas, conocidas bajo la denominación común de Gaiferos y Galván, desarrollan una historia de infancia y juventud, según la cual el niño Gaiferos logra escapar del asesinato ordenado por su padrastro Galván. Ya de joven, Gaiferos regresa a París junto a su innominado tío para vengar la antigua afrenta, matar a Galván y ser reconocido por su madre, que lo creía muerto $^{49}$. Esta trama, que responde a la ancestral "historia del príncipe" de marcado carácter folklórico, presenta llamativas semejanzas con la desarrollada en un novelesco cantar anglo-normando del s. XIII titulado Beuve de Hantone, propuesto por ello como fuente del Gaiferos hispano ${ }^{50}$. Sin entrar en el fondo de esta intrincada cuestión, no podemos dejar de resaltar un motivo común a las dos obras como es el disfraz de peregrino utilizado por el protagonista para volver a su lugar de origen y cobrarse su venganza. Curiosamente, ese motivo

Melisendra, pretendida por muchos príncipes musulmanes y cerca de islamizar por esta razón, es prisionera de Almanzor, rey de Sansueña.

${ }^{48}$ El tema de Sansueña nos parece estrechamente relacionado con el de otros topónimos literarios, como Nobles o Carpentania. La localización de Nobles [de Constantinoble, junto al que aparece mencionado en la versión de Châteauroux de la Chanson de Roland, v. 553, ed. Marjorie Moffat, The Châteauroux Version of the Chanson de Roland: a fully annotated critical text, Berlin-Boston, De Gruyter, 2014 (Beihefte zur Zeitschrift für romanische Philologie, 384): Constantinoble et Sansoigne la large], bascula entre los territorios vecinos al Norte (Gascuña) y Sur (Navarra, Cuenca del Ebro) de los Pirineos, pudiendo ser identificada, dependiendo de la obra que se trate, con la gascona Dax (Gui de Bourgogne, Chronique saintongeaise) o con Pamplona (L'Entrée d'Espagne, La Mort Charlemagne). Cfr. Santiago LóPEZ Martínez-Morás, Épica y Camino de Santiago. En torno al Pseudo-Turpín, A Coruña, Edicións do Castro, 2002, págs. 77-95. Sobre el origen aquitano del tema de la Carpentania, el primer territorio ibérico ocupado por los descendientes de Túbal ya en Jiménez de Rada (Historia de rebus Hispanie, lib. 1, cap. 3), seguido por Alfonso X (General Estoria, ed. Pedro Sánchez Prieto-Borja, et al., Madrid, Fundación José Antonio de Castro, 2009, lib. 1, cap. 3,), cfr. José M.a ANGUITA JAÉN, “Iulius Caesar ut traditur: el primer relato sobre el origen de los vascos (Liber sancti Iacobi 5,7)", Anuario de Estudios Medievales, 50 (2021) [en prensa]. Precisamente, entre las ciudades de la Carpentania alfonsina, junto con Zaragoza, Calahorra y Tarazona, está también Sansueña (Sansonna), a la que se identifica con Pamplona. En coordenadas semejantes debió ubicar mentalmente a Sansueña el autor de la traducción occitana de la Vita sancti Honorati, cuando titula a Sibilia como reÿna de Sancsueyna, y señora del comtat d'Aienes (Agen) et de tota Guascuyna (cfr. Vida de Sant Honorat, ed. Peter T. Ricketts y Cyril P. Hershon, Turnhout, Brepols, 2008, vv. 1427-1428). Para terminar, sin duda está en relación con esta contextualización el hecho de que el resumen que el Toledano hace del Mainet sitúe los palacios de Galiana en Burdeos (cfr. Rodericvs XIMENEZ DE RADA, Historia de rebus Hispanie, lib. 4, cap. 11). Para un tratamiento amplio de esta cuestión, cfr. Víctor MiLlet, "Notas sobre el topónimo Sansueña y su geografía literaria”, Romania, 121, 481-482 (2003), págs. 192-217.

49 Son los romances que comienzan en la edición que nos sirve de referencia con las palabras Estauase la condesa y Vámonos, dixo mi tío. Cfr. Cancionero de romances, fols. 182 y 184.

${ }^{50}$ Cfr. Michael Heintze, "Beuve de Anton en Espagne. A propos des romances sur Gaiferos", Quaderni di fillogia romanza della Facoltà dell’Università di Bologna, 14 (2000), págs. 321-378; BECKMANN, Gualter del Hum..., págs. 65-70, 86-87. 
se encuentra también en las variantes catalanas del episodio del rescate de la esposa de Gaiferos conocidas bajo el nombre de Escriveta, donde el marido no emprende el rescate abiertamente como guerrero, sino bajo el disfraz de peregrino ("Mare tireu me'n la capa i el bastó de pelegrí, aniré de porta en porta a captar el pa i el vi"), razón por la que algunas de las muestras orales recogidas se hayan titulado precisamente así, Lo comte pelegrí, o'l rescat de sa muller ${ }^{51}$. Pues bien, del mismo modo que la cabalgada de Gaiferos por la España musulmana puede encontrar su trasfondo histórico en las expediciones guerreras de Guillermo VIII y Guillermo IX de Aquitania, el motivo del peregrino, adaptado a la trama aventurera de los romances del Gaiferos juvenil o del Beuve de Hantone, podría estar inspirado en la figura de Guillermo X y el hecho más conocido de su biografía: su peregrinación a Santiago de Compostela en hábito de peregrino. En el Assentado está Gaiferos encontramos además un detalle en apariencia intrascendente, pero que bajo esta nueva óptica podría cobrar sentido como un motivo tomado de la historia peregrinal de Guillermo X. En los versos 217-220, se cuenta cómo la llegada de Gaiferos a Sansueña tuvo lugar un viernes, coincidiendo con una celebración local:

\section{Dando estas bozes y otras \\ A Sansueña fue a llegar; \\ Viernes era aquel día \\ Los moros hazen solemnidad.}

Esta solemnidad es la yuma (yumu'ah) u oración del viernes entre los musulmanes, no desconocida como motivo circunstancial en otros romances (De la yuma sale el moro $)^{52}$, y de gran provecho funcional en el romance de Gaiferos, pues la celebración de la fiesta provoca que Almanzor y todos sus caballeros y capitanes estén en la mezquita, dejando paso expedito a Gaiferos para liberar a su mujer. Sin embargo, no podemos dejar de señalar la coincidencia de que la llegada y muerte ejemplar de Guillermo X a Compostela tuviera también lugar en un viernes de gran solemnidad, de hecho el viernes más solemne del año cristiano, y que este hecho tuviera una parte central en el relato ${ }^{53}$.

\footnotetext{
${ }^{51}$ Cfr. Millet, Waltharius..., pág. 187.

52 Cfr. Catalán, Catálogo General..., vol. 3, págs. 321-323.

${ }_{53}$ Nos atreveríamos incluso a apuntar que la centralidad del Viernes Santo en la ejemplar historia de Guillermo X pudo influir en los conocidos relatos sobre Perceval y el Graal. Ya presente en la versión de Chretien de Troyes, resulta mucho más prominente en las plenamente cristianizadas de Boron y Eschenbach. No es este el lugar para proseguir el hilo de este apunte, que podría arrojar algo de luz sobre la contaminación bretona de la historia de infancia y juventud de Gaiferos, con la presencia de Galván, otro de los héroes graálicos, como malvado padrastro de Gaiferos. No olvidemos la vinculación de Chretien de Troyes con la corte de Poitiers, ni la presencia allí de bardos galeses como Blédri ap Davidor, ya desde los tiempos de Guillermo IX.
} 
De ser los temas del viernes y, especialmente, del conde peregrino, algo más que coincidencias casuales, Guillermo X y su peregrinación compostelana también habrían contribuido a la constelación de motivos asociados a la figura literaria de Gaiferos, del mismo modo que sus antecesores pudieron inspirar la cabalgada del héroe por la Hispania sarracena. Esto explicaría la interferencia de elementos jacobeos en los romances del Gaiferos juvenil y en la Escriveta, y sugiere incluso que Gaiferos de Mormaltán y el Gaiferos caballeresco podrían ser la misma figura. No queremos abusar del argumento, pero no podemos dejar de señalar que la biografía literaria del Gaiferos romancesco, de la cual conocemos sus aventuras de infancia, juventud y madurez, quedaría así completada con este postrer episodio de vejez y muerte, reflejado en el romance de Gaiferos de Mormaltán ${ }^{54}$.

\section{Guillermo X de Aquitania y Goffarivs PictVs}

Como ya queda dicho, Murguía fue el primero en identificar a Gaiferos de Mormaltán con Guillermo X de Aquitania, sin dedicar demasiado tiempo a justificarlo. Recogiendo esa propuesta, siglo y medio más tarde Isidoro Millán González-Pardo dedicó toda una monografía para acreditar la identificación del personaje literario con el histórico, llegando a sugerir en distintos lugares de su obra que el nombre de Gaiferos pudiera haber sido un alias operativo del duque Guillermo X de Aquitania ${ }^{55}$. Sin embargo, su trabajo no termina de refrendar con datos concluyentes la sugerente hipótesis. El intento más elaborado de concretarla se basa en el testimonio de Otón de Freising, uno de los cronistas que se hicieron eco de la muerte del duque. Este, en su Crónica, al dar la lista de próceres que anticiparon con su muerte la del emperador Lotario, incluye al conde de Poitiers:

\section{Por el mismo tiempo murieron también el rey Luis [VI de Fran- cia], Enrique [I] de Inglaterra, el arzobispo de Reims Reinaldo y el conde de Poitiers Gaufrido ${ }^{56}$.}

\footnotetext{
${ }^{54}$ Resulta ocioso aclarar que el Gaiferos cuya peripecia conocemos gracias a los romances ya no responde más que muy lejanamente al Gaiffiers carolingio, par de Carlomagno muerto en Roncesvalles y enterrado en Burdeos. Este se nos presenta como yerno de Carlomagno y sobrino de Roldán, ya por primera vez en la Epistola de Rodolfo Tortario, es decir, una generación más joven que el Gaiffiers de las chansons, que a su vez es también una generación más joven que el Waifarius histórico.

${ }^{55}$ Ya el título de su trabajo, Don Gaiferos de Mormaltán X Duque de Aquitania, supone una declaración explícita de su opinión.

${ }^{56}$ Otto Frisingensis, Chronica, ed. Adolf Hofmeister, Otonis episcopi frisingensis Chroncia siue Historia de duabus ciuitatibus, Hannover-Leipzig, Hahn, 1912 (Monumenta Germaniae Historica, Scriptores rerum germanicarum in usum scholarum, 45), lib. 7, cap. 21: Rex etiam Lodewicus et Anglorum Heinricus et Remorum archiepiscopus Reginaldus comesque Pictauiensis Gaufridus eodem tempore obuierunt.
} 
Este conde de Poitiers es, sin lugar a duda, Guillermo X de Aquitania, muerto en el mismo año que el emperador germánico, pero en este texto no es mencionado por su nombre sino por el de Gaufrido. Ante este hecho llamativo, Millán González-Pardo plantea la posibilidad de que Gaufrido haya sido el segundo nombre de Guillermo (lo fue efectivamente de su abuelo Guillermo VIII, Guidus Gaufridus), y de que la cercanía fonética de Gaufridus con Gaifarius haya provocado la confusión ${ }^{57}$. Habrá que convenir en la poca fuerza del argumento, por más enigmático que pueda resultar que Otón de Freising, cronista bien informado e incluso emparentado con Guillermo X, le cambiara el nombre en su obituario. Pero lo hace por Gaufridus, no por Gaifarius.

En la estela de Millán González-Pardo, uno de los objetivos de este trabajo también es apuntalar la teoría de la identidad entre Gaiferos de Mormaltán y Guillermo X de Aquitania, presentando argumentos nuevos y, sobre todo, un testimonio que nos parece alcanzar el valor de prueba. En el punto anterior hemos comprobado cómo algunos de los duques de Aquitania de los siglos XI y XII pudieron contribuir a completar la caracterización y la peripecia del Gaiferos de los romances hispanos; y vimos incluso que entre esos rasgos no faltaban algunos que podrían haberse tomado de la biografía de Guillermo X, el conde peregrino. La argumentación que sigue a continuación nos situará en una esfera diferente e introducirá autores y textos ajenos hasta ahora en la discusión sobre Gaiferos. Estos autores son el poitevino Aimerico Picaud y especialmente el galés Jofre de Monmouth, dos autores estrictamente contemporáneos de Guillermo $\mathrm{X}$ envueltos en lo que nos parece una controversia literaria cuyo marco histórico trataremos de interpretar. Aparte de este punto de encuentro de carácter polémico, las coincidencias, paralelismos y concordancias que unen a estos dos autores son tantas que merecerían un trabajo aparte ${ }^{58}$. En este nos centraremos únicamente en aquello que tiene que ver con Gaiferos y Guillermo X.

En el libro primero de la Historia regum Britanniae de Jofre de Monmouth aparece un personaje denominado Goffarius Pictus, titulado de forma indistinta como rex Aquitaniae y dux Pictauorum ${ }^{59}$. Tanto el personaje como el episodio en que se ve envuelto carecen de base histórica alguna, y todo indica que se trata de una invención novelesca del propio Monmouth. En cualquier caso, a la crítica no le ha pasado desapercibido que el nombre de Goffarius no es más que una

\footnotetext{
57 Millán, Don Gaiferos..., págs. 199-200.

58 Sin entrar en detalles, los puso en relación ya en 1905 Menéndez Pelayo, calificando a Jofre de Monmouth como "el Turpín de esta nueva epopeya", es decir, el creador literario de la materia artúrica. Cfr. Marcelino Menéndez Pelayo, Orígenes de la novela, vol. 1, Madrid, Gredos, 2008 (Nueva Biblioteca Románica Hispánica, 5), pág. 252. Lógicamente, entendemos que Aimerico Picaud es quien le da su forma definitiva al Pseudo-Turpín, parte cuarta del Liber sancti Iacobi.

${ }^{59}$ Galfridvs Monimvtensis, Historia regum Britanniae, ed. Edmond Faral, La légende arthurienne. Études et documents, vol. 3, Paris, Champion, 1993, lib. 1, caps. 18-20.
} 
variante del nombre de Gaifarius-Gaiferos ${ }^{60}$. Dadas las fechas en que escribió Monmouth, es lógico pensar que este tomó el nombre del héroe de la leyenda épica carolingia, ya asimilado, como hemos visto en el punto anterior, a los duques de Aquitania y condes de Poitiers del s. XI y XII. El hecho de que se lo denomine rex Aquitaniae y dux Pictauorum apunta sin duda en esa dirección. Sin embargo, en este caso Goffarius no nos parece una simple evocación onomástica de la casa reinante en Aquitania, como podría ser el rex Gaiferius de Rodolfo Tortario en su Amicus et Amelius, sino una alusión directa y cargada de intención al último titular de la misma, Guillermo X. Veamos por qué creemos que es así.

El marco histórico remoto en que Monmouth introduce a Goffarius Pictus en su historia es el tiempo fundacional de la colonización de Britania por el troyano Bruto, descendiente de cuarta generación de Eneas. Este Bruto fue tomado por Monmouth, al igual que otros personajes de su obra, de la Historia brittonum atribuida a Nennio, dos siglos anterior a la suya ${ }^{61}$. En cualquier caso, la peripecia de Bruto se nos muestra en el relato de Monmouth, en comparación con su fuente, notablemente ampliada y embellecida. Entre los variados elementos (personajes, subtramas, motivos) con que la fértil imaginación del obispo de San Asaph aderezó la relación más parca de Nennio, está el largo episodio, desarrollado en varios capítulos, donde interviene Goffarius Pictus: en el curso de la singladura que iba a llevar a la expedición troyana desde Grecia hasta Britania, esta hace escala en la desembocadura del Loira, en territorio aquitano-poitevino. Inmediatamente surgen las hostilidades entre los troyanos de Bruto y los aquitanos de Gofario, quienes a pesar de luchar en su país y contar con muchos más efectivos, son derrotados de forma repetida y humillante. Detalle fundamental en este episodio es que el protagonismo entre los troyanos recae no en el comandante Bruto sino en su lugarteniente Corineo, personalmente responsable de abrir las hostilidades, y destacadísimo en los repetidos enfrentamientos con los pictavinos, entre cuyas filas sembrará la destrucción enarbolando su mortífera hacha doble. Este Corineo, creación pura de Monmouth ${ }^{62}$, es en su obra el héroe epónimo de Cornualles ${ }^{63}$, del mismo modo que Bruto (Bryto) lo es de Britania. Personaje de fuerza y talla extraordinarias, Corineo será en su momento el encargado de librar a Britania en general, y a Cornualles en particular, de la

\footnotetext{
${ }^{60}$ Edmond FARAL, La légende arthurienne. Études et documents, vol. 2, Paris, Champion, 1993, pág. 85.

${ }^{61}$ Nennivs, Historia brittonum, ed. Theodor Mommsen, Historia brittonum cum aditamentis Nennii, en Chronica minora: saec. IV, V, VI, VI, Berlin, Weidmann, 1898 (Monumenta Germaniae Historica, Auctores Antiquissimi, 13), cap. 13. Por medio de Bruto, los britones altomedievales, del mismo modo que los romanos y los francos, se habían propuesto ennoblecer sus orígenes, situándolos en Troya.

${ }^{62}$ Sobre las características y el nombre (virgiliano) de Corineo, así como las fuentes que sirvieron a Monmouth de inspiración, cfr. FARAL, La légende arthurienne..., vol. 2, págs. 84-87.

${ }^{63}$ En un primer momento, Cornualles llevará el nombre de Corinea, que con el tiempo se mudará en Cornubia. Cfr. Galfridvs Monimvtensis, Historia regum Britanniae, 1, 21.
} 
primitiva raza de los gigantes ${ }^{64}$, y ya veremos las implicaciones que eso tiene en esta argumentación. De momento, es importante retener que Jofre de Monmouth deja bien claro que el enfrentamiento de Gofario no es tanto con Bruto, epónimo de los futuros británicos, como con Corineo, epónimo de los futuros córnicos o cornualleses.

En cuanto al segundo autor involucrado en esta argumentación, se trata de Aimerico Picaud, conocido como uno de los últimos compiladores del Liber sancti Iacobi (Códice Calixtino), responsable de su orientación definitiva y autor de sus textos más característicos. Entre ellos, el que aquí nos interesa, es un pasaje de complicada exégesis que cobra buena parte de su sentido precisamente en el marco de relaciones de Aimerico con Jofre de Monmouth y Guillermo X que proponemos. Forma parte de la quinta parte del Liber sancti Iacobi, la popular Guía del peregrino medieval; y dentro de esta sección, del capítulo 7 , De nominibus terrarum et qualitatibus gencium que in ytinere sancti Iacobi habentur. El planteamiento teórico de este capítulo, de acuerdo con su título, es una descripción geo-etnográfica de los territorios y las gentes del Camino de Santiago entre Tours y Santiago de Compostela, aunque lo que el lector se encuentra realmente en él es un tratado dedicado casi monográficamente -tres cuartas partes del capítulo- a los vascos, mezcla de informaciones veraces y de infundios malintencionados ${ }^{65}$. El colofón de este tratado vasco es un extraño relato etnogenético, ambientado en el tiempo de Julio César (íncipit: Iulius Caesar ut traditur) donde se explica el origen de vascos y navarros como el fruto de una fusión entre mujeres autóctonas y soldados extranjeros, mercenarios de Roma ${ }^{66}$. Aunque estos mercenarios pertenecen a tres pueblos distintos, nubios, escotos y cornualleses, en realidad son los segundos, los escotos, los que de verdad interesan, puesto que el objetivo del relato es explanar en términos históricos las semejanzas de aspecto y costumbres de vascos y escotos ${ }^{67}$, planteamiento exacto, por cierto, al de Jofre de Monmouth en su Historia regum Britanniae ${ }^{68}$. Esta

\footnotetext{
${ }^{64}$ Galfridvs Monimvtensis, Historia regum Britanniae, 1,21.

${ }^{65}$ Para un análisis de este "tratado" vasco, cfr. José M. a AnguitA JAÉn, “Bascli et Nauarri: los vascos del s. XII según el Liber Sancti Iacobi”, Veleia, 16 (1999), págs. 303-327.

${ }^{66}$ Para un análisis pormenorizado de esta fantasiosa etnogénesis, cfr. ANGUITA, "Iulius Caesar ut traditur..." [en prensa].

${ }^{67}$ Cfr. las palabras con las que se introduce el relato: Tradi solet illos (sc. basclos) ex genere Scotorum descendisse, pro eo quod similes illis sunt moribus et similitudine (Liber sancti Iacobi, 5,7).

${ }^{68}$ Galfridvs Monimvtensis, Historia regum Britanniae, 1,45-46. Se trata de la historia del rey britón Gurguint Barbtruc y del vasco Partholoim, transformación del hispano Partholomeus de la Historia brittonum (13), responsable de la primera colonización de Irlanda. El hecho de que Monmouth convierta a Partholomeus y sus expedicionarios hispanos, ancestros de los escotos, en vascos (basclenses), justamente en el mismo momento en que Picaud propone que los vascos proceden de los escotos no es, evidentemente, casualidad. Para un desarrollo más amplio de esta cuestión, cfr. ANGUiTA, "Iulius Caesar ut traditur..." [en prensa].
} 
es una de las coincidencias de Jofre y Aimerico que mencionábamos más arriba, $\mathrm{y}$ un buen indicio de que ambos autores formaron parte de unos ambientes intelectuales en los que, entre otras cosas, se habían puesto sobre la mesa cuestiones como esta. En todo caso, el Iulius Caesar ut traditur de Aimerico Picaud nos interesa aquí por otra razón. Como apuntábamos más arriba, los mercenarios romanos que se mezclaron con las mujeres autóctonas para dar lugar al pueblo vasco-navarro eran de tres etnias distintas: los nubios, que tienen como función explicar el color más oscuro de los navarros respecto a los vascos; los escotos, razón principal del relato; y unos cornualleses que no tienen ninguna justificación de tipo funcional en el mismo, puesto que los escotos bastan para ilustrar el parecido de los vascos con los pueblos celtobritánicos. Su presencia solamente tiene una razón, que es la de afrentar a los habitantes de Cornualles. Y es que, efectivamente, según el relato de Aimerico los mercenarios cornualleses no son simplemente cornubiani, sino cornubiani caudati, es decir, 'cornualleses provistos de una cola dorsal', lo cual en los códigos de la época presenta una doble connotación despectiva de primitivismo y cobardía ${ }^{69}$.

Teniendo en cuenta que Aimerico y Jofre escribieron sus respectivos textos prácticamente al mismo tiempo (1134-1136), no creemos que sea casual que mientras uno introduce en su relato de forma gratuita a unos cornubiani caudati, el otro intercale en el periplo de los futuros britones una larga y superflua escala en Aquitania que sirve únicamente para que Corineo derrote de forma bochornosa a Gofario Picto. De este modo, mientras uno endosa a los cornualleses una cola dorsal que los tacha de cobardes e incivilizados, el otro responde puntualmente a ambos insultos por medio de la figura de Corineo. Este devuelve, por una parte, el baldón de la cobardía a los pictavinos; por otra, libra a Cornualles del estigma del primitivismo, acabando con la raza autóctona de los gigantes, y dotando al país de uno de los cuños civilizadores más apreciados de su tiempo, el troyano.

Este cruce de insultos étnicos entre los dos autores cobra sentido en un contexto histórico definido, que explica también por qué Monmouth alude de forma tan hostil a Guillermo X de Aquitania, velado - o intuimos que no tanto para sus contemporáneos- bajo la figura antipática y fracasada del remoto Gofario Picto. Prácticamente por las mismas fechas en que Jofre concluía su historia, la muerte de Enrique I de Inglaterra en 1135 dio lugar a una larga guerra dinástica

\footnotetext{
${ }^{69}$ La relación de la cola ofidia con la autoctonía y, por ende el primitivismo, es bien conocida desde la Mitología griega (gigantes, reyes atenienses, etc). Para la aplicación particular del adjetivo caudatus a los habitantes de las Islas Británicas durante la Edad Media, cfr. George NeILson, Caudatus anglicus. A Medieval Slander, Edinburgh, George P. Johnston, 1896. En cuanto a la utilización en latín, a partir del s. XI, del adjetivo en el sentido de 'cobarde', cfr. Albert BlaISE, Lexicon Latinitatis Medii Aeuii Turnhout, Brepols, 1975, s.v. caudatus.
} 
entre su sobrino Esteban de Blois, que se hizo con el trono inglés por la fuerza, y su hija la "emperatriz" Matilde, que hizo valer sus derechos desde su posición de condesa de Anjou. Como aliado de esta última, también entró en campaña Guillermo X de Aquitania, y lo hizo de forma activa, a juzgar por las palabras de Orderico Vital, quien pone la causa de su peregrinación penitencial precisamente en los excesos cometidos en Normandía durante el conflicto en torno al trono inglés. Por la otra parte, el señor de Cornualles de este tiempo, el bretón Alano el Negro, luchó en defensa de los intereses de Esteban de Blois. Aquí tenemos un contexto bélico que enfrenta directamente a los señoríos del Poiteau y Cornualles, como aliados de los distintos pretendientes al trono inglés. No es descabellado suponer, en ese escenario, un encontronazo real entre cornualleses y poitevinos que diera lugar a la animadversión mutua que reflejan tanto la Historia regum Britanniae como el Iulius Caesar ut traditur del Liber sancti Iacobi.

Comprobamos, por tanto, que los textos de Monmouth y Picaud, contemporáneos entre sí, lo son también de un conflicto que enfrentó circunstancialmente a Cornualles y el Poiteau, en el marco más amplio y prolongado de la guerra dinástica inglesa. Aunque las respectivas biografías de estos dos autores son mal conocidas, sobran los indicios que relacionan a Jofre de Monmouth con ambientes cercanos al rey Esteban de Blois ${ }^{70}$, del mismo modo que el trato privilegiado que concede a Cornualles a lo largo de su obra sugiere una estrecha vinculación, siquiera afectiva, con esta región. En cuanto a Aimerico, de biografía aún más desconocida, también contamos con indicios que permiten relacionarlo, incluso estrechamente, con Guillermo X de Aquitania: el lugar del que dice proceder, Parthenay-le-Vieux, es el mismo en que tenía establecido su residencia principal Guillermo $^{71}$. Los infundios propagandísticos del tratado vasco (o anti-vasco), del Liber sancti Iacobi encuentran su trasfondo político en el conflicto del ducado de Aquitania con las baronías vasco-francesas, apoyadas de forma más o menos declarada por el Reino de Navarra ${ }^{72}$. Parece claro que con ellos Aimerico está

\footnotetext{
${ }^{70}$ El principal, y el que más nos interesa por las fechas que se barajan, es sin duda la versión de la Historia regum Britanniae del ms. 568 de Berna, que Monmouth le dedicó al rey Esteban, y que ha sido datada por los especialistas entre 1135 y 1138. Cfr. FARAL, La légende arthurienne..., vol. 2, págs. 10-14.

${ }_{71}$ Prácticamente los únicos datos explícitos que tenemos de Aimerico Picaud son su propio nombre y el de su patria chica, Parthenay-le-Vieux (Aimericus Picaudus de Partiniaco Vetero). Con ellos, una bula (falsa) de Inocencio II inserta al final del Códice Calixtino (fol. 192) dota a Aimerico de un salvoconducto, identificándolo como portador-donante del códice a la Iglesia Compostelana (Liber sancti Iacobi, Apéndices). En cuanto a Guillermo X, en 1135 tuvo lugar en Parthenay-le-Vieux un sonado encuentro entre Guillermo X y san Bernardo de Claraval, que había acudido allí para conseguir que el duque, excomulgado, cesara en su apoyo al antipapa Anacleto y volviera al partido del papa, precisamente el Inocencio II de la bula a Aimerico (Arnaldvs Bonaevallensis, Vita I Bernardi, lib. 2, cap. 6).

${ }^{72}$ Recuérdese el asedio de Bayona por Alfonso I el Batallador entre 1130 y 1134 . Precisamente en el tratado vasco del Liber sancti Iacobi $(5,7)$, Aimerico Picaud cuenta al rey de Aragón entre los responsables de los desafueros que los peregrinos sufrían a su paso por el País Vasco Francés, llegando a pedir la exco-
} 
sirviendo aquí los intereses de su señor del mismo modo que lo hace cuando introduce sin venir a cuento en su relato etnogenético vasco a unos cornubiani caudati.

Desconocemos cómo fue la secuencia del intercambio de golpes entre Monmouth y Picaud, pero nos atreveríamos a sugerir que el Iulius Caesar ut traditur es algo anterior, y que Jofre contestó por elevación, introduciendo en su relato al propio señor de Aimerico, el duque Guillermo X, disfrazándolo de Goffarius Pictus. Los círculos de allegados y de personas al tanto, que serían sin ir más lejos, dada la talla del personaje y su red de relaciones, todas las cancillerías de la Europa occidental de su tiempo, sabrían interpretar la malicia de Jofre de Monmouth, bien porque Gaiferos fuera ya un sobrenombre conocido del duque, bien porque la asimilación del antiguo héroe con la casa reinante aquitana haría inmediatamente inteligible la broma, y la figura de Guillermo quedaría automáticamente identificada como Goffarius, como Gaiferos.

\section{Conclusiones}

Jofre de Monmouth y su Goffarius Pictus nos ofrecen un testimonio contemporáneo que certifica la hipótesis de que Gaiferos pudo ser efectivamente un alias operativo del duque que murió como peregrino en Santiago de Compostela en 1137. Ello aclararía el aparente sinsentido de que, en el reflejo literario del que fue el hecho más conocido de su biografía, aparezca cubierto bajo la máscara de Gaiferos de Mormaltán.

De todas formas, y aunque esto haya sido así, no deja de resultar llamativo el cambio del nombre real por el sobrenombre. La razón de esto podría responder a la propia voluntad del duque: el tono de sincero arrepentimiento y desprendimiento de las glorias mundanas de su testamento sugieren que su peregrinación pudo realizarse, si no de forma anónima, sí de forma discreta, quizá bajo la identidad de Gaiferos. No conviene olvidar que Guillermo no murió solo y abandonado, sino rodeado por los próceres de su reino, a los que había hecho viajar hasta Compostela para encomendarles sus últimas voluntades. Si fue enterrado de forma anónima y humilde en la Catedral de Santiago en lugar de ser trasladado al panteón familiar de Montierneuf, fue por propia voluntad. Si esto tuvo lugar de forma reservada, sin grandes ceremonias ni publicidad, es lógico pensar

munión para él. Por otra parte, sabemos que, no mucho antes de que Bayona fuera sitiada por Alfonso I, la villa había recibido fuero del duque Guillermo IX el Trovador. Para los pasajes del Liber sancti Iacobi relativos a los portazgos inicuos en el País Vasco Francés, cfr. ANGUITA, “Bascli et Nauarri...”, págs. 303327. Sobre las franquicias concedidas por el duque aquitano a Bayona, aludidos en las confirmaciones posteriores de Ricardo Corazón de León, cfr. Frédéric Boutulle "Richard Coeur de Lion à Bayonne et dans le Labourd”, Annales du Midi, 123/275 (2011), págs. 325-351. 
que fue por propia voluntad, y ello quizá explique el hecho extraño de que la historiografía hispana de su tiempo no se hiciera eco de un acontecimiento tan fuera de lo común. Sin embargo, no conviene olvidar tampoco que la muerte del duque, con su mucho de ejemplar y su algo de extraordinario, está ligada de forma casi indisoluble a la devoción jacobea ${ }^{73}$, y cabe imaginarse el interés de la sede compostelana en darle alguna notoriedad al suceso. Se podría haber arbitrado, entonces, una forma de hacerlo sin faltar a la voluntad del difunto, divulgándolo por medio de juglares y poetas populares, que lo habrían cantado substituyendo el nombre del protagonista real, el gran duque Guillermo X de Aquitania, por su sobrenombre, Gaiferos.

Lo cierto es que el cambio de nombre supone prácticamente una prueba de que los materiales del Gaiferos de Mormaltán no son invención de Murguía, pues ni este ni nadie de su tiempo tuvo constancia de la asociación del nombre de Gaiferos al de Guillermo X, y deberá admitirse que, desde el punto de vista de un falsificador del s. XIX, el pseudónimo Gaiferos no aporta nada a un romance que, de haber preservado el nombre real del protagonista original, habría resultado mucho más convincente, teniendo en cuenta que se basa en hechos auténticos. En cualquier caso, la realidad es que entre la primera mitad del siglo XII, cuando pudo ponerse en circulación una tonada de estas características, y la segunda mitad del siglo XIX, cuando Murguía publica su Gaiferos de Mormaltán, no hay más huellas de su existencia que las puntuales concordancias del panegírico de Ricardo Pictavense y del Cronicón de Saint-Maixent, o los reflejos del romancero viejo (y la Escriveta catalana) donde el motivo peregrinal se inserta de forma accesoria entre los materiales épicos de Gaiferos. Estos reflejos, por pálidos que resulten, apuntan sin embargo a una tradición que liga el nombre y la peripecia de Gaiferos con la peregrinación compostelana, aunque se trate de una tradición indocumentada en su forma original y en todos los vericuetos posibles de su recorrido por el tiempo. Dando por bueno que uno de los ramales de esta tradición logró llegar al conocimiento de Manuel Murguía, la cuestión que se plantea es: ¿qué es exactamente lo que llegó y en qué condiciones lo hizo? No lo sabemos, puesto que Murguía nos negó esa información, así que toda explicación posible deberá adentrarse necesariamente en el proceloso terreno de las hipótesis. Por una parte, tenemos unos materiales literarios antiguos sobre el argumento del Gaiferos de Mormaltán. Por otra, el dictamen de unos especialistas en literatura tradicional que niegan la autenticidad genuina de la pieza. Una explicación que

\footnotetext{
${ }^{73}$ Recuérdese que la muerte del duque tuvo lugar en una fecha más que señalada, el Viernes Santo de un año, 1137, en el que la fiesta de Santiago caía en domingo, es decir, en un precedente, quizá un embrión, de año santo compostelano (cfr. n. 20). Recordemos, además, que los esponsales de Leonor, la hija de Guillermo, y el futuro Luis VII tuvieron lugar precisamente en ese domingo 25 de julio, fiesta de Santiago ¿quizá como acción de gracias por la buena muerte del padre y suegro?
} 
podría conciliar estas dos premisas en apariencia excluyentes es que los materiales del Gaiferos peregrino llegaran al s. XIX en un estado tan mermado y deficiente, que hubieran obligado a una recreación prácticamente completa de los mismos. Si las cosas hubieran sido así, Murguía habría dispuesto de poco más que el nombre del protagonista y un núcleo argumental muy básico para componer su Gaiferos de Mormaltán. Teniendo esto en cuenta, quizá cabría repensar la catalogación del romance como simple falsificación para pasar a considerarla como una pieza facticia realizada a partir de elementos tradicionales.

\section{BIBLIOGRAFÍA}

Alfonso X, General Estoria, ed. Pedro Sánchez Prieto-Borja, et al., Madrid, Fundación José Antonio de Castro, 2009, 10 vols.

Anguita Jaén, José M. a " “Bascli et Nauarri: los vascos del s. XII según el Liber Sancti Iacobi”, Veleia, 16 (1999), págs. 303-327.

Anguita Jaén, José M. a, "Peregrinatio: la conformación de un concepto, la transformación de una realidad", en Santiago López Martínez-Morás, Marina Meléndez Cabo, Gerardo Pérez Barcala (coords.), Identidad europea e intercambios culturales en el Camino de Santiago (siglos $X-X V$ ), Santiago de Compostela, Universidad de Santiago de Compostela, 2013, págs. 151-168.

Anguita Jaén, José M. a " "Iulius Caesar ut traditur: el primer relato sobre el origen de los vascos (Liber sancti Iacobi 5,7)”, Anuario de Estudios Medievales, 50 (2021), en prensa.

Arnaldus Bonaevallensis, Vita I Bernardi, ed. Jean Mabillon, en Patrologia Latina, vol. 185, Paris, Jean-Paul Migne, 1860, cols. 267-302.

Beckmann, Gustav Adolf, Gualter del Hum-Gaiferos-Waltharius, Göttingen, De Gruyter, 2010.

Blaise, Albert, Lexicon Latinitatis Medii Aeuii, Turnhout, Brepols, 1975.

Boutulle, Frédéric, "Richard Coeur de Lion à Bayonne et dans le Labourd", Annales du Midi, 123/275 (2011), págs. 325-351.

Cancionero de romances. Anvers 1550, ed. Antonio Rodríguez Moñino, Madrid, Castalia, 1967 (Romanceros de los siglos de oro, 1).

Cappelli, Augusto, Cronologia, cronografia e calendario perpetuo: dal principio dell'Era Cristiana ai nostri giorni. Tavole cronologico-sincrone e quadri sinottici per verificare le date storiche, quinta edizione aggiornata, Milano, Ulrico Hoepli, 1983.

Catalán, Diego, et al., Catálogo General del Romancero, Madrid, Seminario Menéndez-Pidal, 1983, 3 vols.

Cercamón, Poesies, ed. Alfred Jeanroy, Les poesies de Cercamon, Paris, Honoré Champion, 1922 (Classiques français du Moyen Age, 27).

Chanson de Roland, ed. Marjorie Moffat, The Chateauroux Version of the Chanson de Roland: a fully annotated critical text, Berlin-Boston, De Gruyter, 2014 (Beihefte zur Zeitschrift für romanische Philologie, 384). 
Chronica Adefonsi Imperatoris, ed. Antonio Maya Sánchez, Chronica hispana saeculi XII. Pars I, Turnhout, Brepols, 1990 (Corpus Christianorum. Continuatio Mediaevalis, 71), págs. 109-248.

Chronica comitum Pictauiae, ed. Leopold Delisle [Ex fragmentis chronicorum comitum Pictaviae, ducum Aquitaniae, auctore ut uidetur, monacho S. Maxentii], Paris, Victor Palmé, 1887 (Rerum Gallicarum et Francicarum Scriptores. Nouvelle edition, 12).

Chronica Mauriniacensis, ed. Léon Mirot, La Chronique de Morigny (1095-1152), Paris, Libraire de Alphonse Picard et fils, 1909.

Chronica sancti Maxentii, ed. Leopold Delisle [Ex chronico sancti Maxentii quod uulgo Malleacense dicitur], Paris, Victor Palmé, 1887 (Rerum Gallicarum et Francicarum Scriptores. Nouvelle edition, 12), págs. 400-408.

Chroniques de Saint-Denis, ed. Pauline Paris, Les grandes chroniques de France selon que elles sont conservées en l'eglise de Saint-Denis, Paris, Techener, 1836-1838, 6 vols.

Cuyper, Willem [Guillelmus Cuper], "Sanctus Iacobus Maior" [Iul.VI, dies 25], en Acta Sanctorum Bollandistarum, vol. 6, Amberes, apud Jacobum du Moulin, 1729, cols. 4A-114D.

Faral, Edmond, La légende arthurienne. Études et documents, Paris, Champion, 1993, 3 vols. (Bibliothèque de l'École des Hautes Études, 255, 256, 257).

Fernández Ordóñez, Inés, "El tema épico-legendario de Carlos-Mainete y la transformación de la historiografía medieval hispánica entre los siglos XIII y XIV”, en Jean-Philippe Genet (coord.), L'histoire et les nouveaux publics dans l'Europe médiévale (XIIIe-XIVe siècles). Actes du colloque International organisé par la Fondation Européene de la Science á la Casa Velasquez, Madrid, 23-24 avril 1993, Paris, Publications de la Sorbonne, 1997, págs. 89-112.

Forneiro, José Luis, El Romancero tradicional de Galicia, una poesía entre dos lenguas, Oiartzun, Sendoa, 2000.

Forneiro, José Luis, “Mais textos para a produçâo de Murguía em lingua galega”, en Congreso sobre Manuel Murguía, Santiago de Compostela, Consellería de Cultura, Comunicación social e Turismo, 2001, págs. 169-188.

Forneiro, José Luis, "Gaiferos de Mormaltán: Cantiga medieval? Romance tradicional?", Vieiros [en línea] (06-05-2010), disponible en <http:/www.vieiros.com/columnas/opinion/1198/gaiferos-de-mormaltan-cantiga-medieval-romance-tradicional $>$ [Consulta: $11 / 03 / 2020]$.

Forneiro, José Luis, "El Romancero tradicional de Galicia. Estado de la cuestión”, Boletín de Literatura Oral, 1 (2017), págs. 105-130.

Fredegarius, Chronica, ed. Bruno Krusch, Chronicarum quae dicuntur Fredegarii Scholastici libri IV cum continuationibus, Hannover, Hahn, 1888 (Monumenta Germaniae Historica, Scriptores Rerum Merovingicarum, 2), págs. 1-193.

Galfridus Monimutensis, Historia regum Britanniae, ed. Edmond Faral, La légende arthurienne. Études et documents, vol. 3, Paris, Champion, 1993, págs. 71-303.

Heintze, Michael, "Beuve de Anton en Espagne. A propos des romances sur Gaiferos", Quaderni di fillogia romanza della Facoltà dell’Università di Bologna, 14 (2000), págs. 321378 . 
Henschen, Godfried [Godefridus Henschenius], "Sanctus Guillelmus Eremita apud Stabulum Rodis in Etruria" [1Feb. II, dies 10], Acta Sanctorum Bollandistarum, vol. 2, Amberes, 1658, cols. 441D-443A.

Hugo Pictauinus, Chronicon abbatiae Vizeliacensis, ed. Robert B.C. Huygens, Monumenta Veziliacensia: textes relatifs a l'histoire de l'abbaye de Vézelay, Turnhout, Brepols, 1976 (Corpus Christianorum. Continuatio Mediaevalis, 42), págs. 395-607.

Jehan Bodel, Chanson des Saisnes, ed. Anette Péry Brasseur, Genève, Droz, 1989 (Textes littéraires français, 369), 2 vols.

Lacolonie, Jean-Martin de, Histoire curieuse et remarquable de la ville et province de Bordeaux, Bruxelles, aux dépens de la Compagnie, 1760, 3 vols.

Liber sancti Iacobi, ed. Klaus Herbers y Manuel Santos Noia, Liber sancti Iacobi. Codex Calixtinus, Santiago de Compostela, Xunta de Galicia, 1999.

Longueval, Jacques, Histoire de l'Eglise Gallicane, Paris, Montalant-Coignard-Guerin-Rollin, 1734,8 vols.

López Ferreiro, Antonio, Historia de la Santa A.M. Iglesia de Santiago de Compostela, Santiago de Compostela, Seminario Conciliar Central, 1898-1911, 11 vols.

López Martínez-Morás, Santiago, Épica y Camino de Santiago. En torno al Pseudo-Turpín, A Coruña, Edicións do Castro, 2002.

Mainet, ed. Gaston Paris, "Mainet, fragments d'une chanson de geste du XII" siècle", Romania, 4 (1875), págs. 305-337.

Mariana, Juan de, Historiae de rebus Hispaniae libri XXX, Moguntia, Impensis Danielis ac Davidis Aubriorum et Clementis Schleichii, 1619, 2 vols.

Menéndez Pelayo, Marcelino, Orígenes de la novela, Madrid, Gredos, 2008 (Nueva Biblioteca Románica Hispánica, 5, 6), 2 vols.

Menéndez Pidal, Ramón, La España del Cid, Madrid, Espasa-Calpe, 1969, 2 vols.

Millán González-Pardo, Isidoro, Don Gaiferos de Mormaltán, X Duque de Aquitania, Santiago de Compostela, Follas Novas, 2009.

Millet, Víctor, Waltharius-Gaiferos: über den Ursprung der Walthersage und ihre Beziehung zur Romanze von Gaiferos und zur Ballade von Escriveta, Frankfurt et al., Peter Lang, 1992.

Millet, Víctor, "Notas sobre el topónimo Sansueña y su geografía literaria”, Romania, 121, 481-482 (2003), págs. 192-217.

Moisan, André, Répertorie des noms propes de personnes et de lieux cités dans les chansons de geste françaises et les ouvres étrangères derivées, t. I, vol. 1, Droz, Généve, 1986.

Montaner Frutos, Alberto, "La mora Zaida, entre historia y leyenda (con una reflexión sobre la técnica historiográfica alfonsí)", en Barry Taylor y Geoffrey West (eds.), Historicist Essays on Hispano-Medieval Narrative. In Memory of Roger M. Walker, London, Maney Publishing 2005, págs. 272-352.

Murguía, Manuel, Galicia, Barcelona, Establecimiento tipográfico-editorial de Daniel Cortezo y C. a, 1888 (España. Sus monumentos y artes, su naturaleza é historia), 2 vols.

Neilson, George, Caudatus anglicus. A Medieval Slander, Edinburgh, George P. Johnston, 1896. 
Nennius, Historia brittonum, ed. Theodor Mommsen, Historia brittonum cum aditamentis Nennii, en Chronica minora: saec. IV, V, VI, VI, Berlin, Weidmann, 1898 (Monumenta Germaniae Historica, Auctores Antiquissimi, 13), págs. 111-222.

Ordericus Vitalis, Ecclesiastica historia, ed. André Du Chesne, Orderici Vitalis Ecclesiastica historia, en Patrologia Latina, vol. 188, Paris, Jean-Paul Migne, 1855, cols. 17-979.

Otto I Frisingensis, Chronica, ed. Adolf Hofmeister, Otonis episcopi frisingensis Chroncia siue Historia de duabus ciuitatibus, Hannover-Leipzig, Hahn, 1912 (Monumenta Germaniae Historica, Scriptores rerum germanicarum in usum scholarum, 45), págs. 1-457.

Pardiac, Jean-Baptiste, Histoire de S. Jacques le Majeur et du pèlerinage a Compostelle, Bordeaux, L. Coderc et C ${ }^{\text {ie }}, 1863$.

Richardus Pictauiensis uel Cluniacensis, Chronica cum praefatione ad Petrum Venerabilem (planctus ad Guillelmum X ducem Aquitaniae), ed. Leopold Delisle "Ex chronicone Richardi Pictavensis, monachi cluniacensis" en Rerum Gallicarum et Francicarum Scriptores. Nouvelle edition, vol. 12, Paris, Victor Palmé, 1887, págs. 411-417.

Rodericus Ximenez de Rada, Historia de rebus Hispanie siue Historia Gothica ed. Juan Fernández Valverde Opera omnia I, Turnhout, Brepols 1987 (Corpus Christianorum. Continuatio Mediaevalis, 72).

Rodríguez Fer, Claudio, "O pornógrafo", en Primeiras Xornadas de Teatro na Radio. 17 a 19 de maio de 1989, Lugo, Radio 5; Caixa Galicia, 1989.

Rodríguez-Moñino, Antonio, Diccionario bibliográfico de pliegos sueltos poéticos (siglo XVI), Madrid, Castalia, 1970.

Rodríguez-Moñino, Antonio, Manual bibliográfico de cancioneros y romanceros, Madrid, Castalia, 1973-1978.

Rodulphus Tortarius, Epistula II ad Bernardum, ed. Marbury B. Ogle y Dorothy M. Schullian, Rodulfi Tortarii Carmina, Roma, American Academy in Rome, 1933, págs. 256-267.

Sugerus sancti Dionysii, Vita Ludouici ed. Albert Lecoy de la Marche, en Ouvres complètes de Suger, Paris, chez $\mathrm{M}^{\mathrm{me}}$. Ve. Jules Renard, 1867, págs. 1-149.

Valenciano, Ana, Romancero Xeral de Galicia. Os romances tradicionais de Galicia, Santiago de Compostela; Madrid, Centro de Investigaciones Ramón Piñeiro; Fundación Ramón Menéndez Pidal, 1998.

Vida de sant Honorat, ed. Peter T. Ricketts y Cyril P. Hershon, Turnhout, Brepols, 2008.

Vita sancti Honorati, ed. Bernhard Munke, Halle, Ehrhardt Karras, 1911.

Waltharius, ed. Karl Strecker, Weimar, Böhlaus, 1951 (Monumenta Germaniae Historica, Poetae Latini Medii Aevi 6, 1), págs. 1-86.

Zurita, Jerónimo, Anales de la Corona de Aragón, Zaragoza, Casa de Pedro Bernuz, 1562, 2 vols. 
